\title{
EL COMISO COMO ESTRATEGIA FRENTE A LA CORRUPCIÓN EN ALEMANIA: INTERPRETACIÓN JURISPRUDENCIAL*
}

\author{
Margarita Roig Torres**
}

Resumen: En Alemania la privación de los bienes del delito se hace a través de dos figuras, el comiso (Verfall) de las ganancias ilícitas, y la confiscación (Einziehung) de los productos y de los objetos empleados en la preparación o ejecución del hecho. Respecto al primero la jurisprudencia afirma que no es una pena o una sanción asimilada a ella, sino una medida para la ordenación del patrimonio y la estabilización de la norma, mientras la segunda es una pena accesoria. En el comiso rige el "principio bruto" (Bruttoprinzip), de modo que se requisa lo obtenido ilícitamente sin descontar los costes de ejecución. Además, en los delitos de cohecho no sólo abarca los beneficios obtenidos, sino también

Recibido: diciembre 2018. Aceptado: enero 2018

* Este artículo ha sido realizado en el marco del Proyecto "Nuevos instrumentos jurídicos en la lucha contra la corrupción pública: propuestas desde el Derecho penal y el Derecho constitucional" (DER2015-71176-R), concedido por el Ministerio de Justicia y Competitividad.

** Profesora Titular de Derecho Penal (Acred. a catedrática). ORCID ID: 0000-0003-1947-6853

Departamento de Derecho Penal. Facultad de Derecho de la Universidad de Valencia. Avda. dels Tarongers, s/n, 46022, Valencia. Email: margarita. roig@uv.es 
las ganancias esperables. El sistema es enteramente distinto al regulado en el Código penal español, donde se asigna al decomiso un carácter civil y patrimonial, basándolo en muchos casos en presunciones legales respecto al origen ilegal de los bienes.

Palabras clave: comiso; confiscación; Verfall; Einziehung; corrupción; principio bruto.

\section{THE CONFISCATION AS A STRATEGY AGAINST CORRUPTION IN GERMANY: JURISPRUDENTIAL INTERPRETATION}

Abstract: In Germany, deprivation of property of the crime is done through two institutions, the seizure (Verfall) of illicit profits, and the confiscation (Einziehung) of the products and objects used in the preparation or execution of the act. Regarding the first, the jurisprudence declares that it is not a penalty or a sanction assimilated to it, but a measure for the management of the patrimony and the stabilization of the norm, while the second is an accessory penalty. In seizure the "gross principle" (Bruttoprinzip) acts, so that what is obtained illegally is seized without deducting the costs of execution. In addition, corruption crimes cover not only the profits made but also the expected profits. The system is entirely different from that regulated in the Spanish Penal Code, where confiscation is assigned a civil and patrimonial character, based in many cases on legal presumptions regarding the illegal origin of the property.

Keywords: seizure, confiscation, Verfall, Einziehung, corruption, gross principle.

\section{Introducción}

La corrupción es uno de los grandes retos a los que se enfrenta nuestra política criminal actual, por su incremento en los últimos años, pero también por la gran preocupación que genera en la sociedad y la consiguiente merma de la confianza en el Estado de Derecho. Según el último barómetro del Centro de Investigaciones Sociológicas -CIS- los ciudadanos consideran que es el segundo problema más grave, a continuación del paro, pero además las opiniones en este sentido han experimentado un 
notable ascenso ${ }^{1}$. De todas formas, se trata de un fenómeno común a los países europeos ${ }^{2}$, donde están proliferando las reformas legales para tratar de combatirlo ${ }^{3}$. Desde hace varias décadas los organismos internacionales vienen destacando el móvil de lucro que está detrás de ciertas modalidades de delincuencia y han acentuado la importancia del comiso como instrumento para prevenir estas conductas ${ }^{4}$. Por otra parte, esta conexión que en un principio se redujo al tráfico de drogas y la delincuencia organizada, se ha extendido a otras formas de criminalidad tam-

1 El paro es la principal preocupación para el $71,4 \%$ de los encuestados y la corrupción para el 51,3\%. (http://www.cis.es/cis/export/sites/default/Archivos/Indicadores/documentos_html/TresProblemas.html).

2 Según el «Eurobarómetro» de 2013 sobre la percepción de la corrupción en los estados miembros, el 76\% de los consultados consideraba que está muy extendida en su propio país. Los mayores porcentajes los tenían, Grecia (99\%), Italia (97\%), España, Lituania y República Checa (95\%), Eslovenia (91\%) y Portugal (90\%). Los índices más bajos corresponden a Dinamarca (20\%), Finlandia (29\%), Luxemburgo (42\%) y Suecia (44\%). Informe de la Comisión al Consejo y al Parlamento Europeo sobre la lucha contra la corrupción en la UE, de 3 de febrero de 2014, COM (2014) 38, pp. 7 y ss, (http://ec.europa.eu/dgs/home-affairs/e-library/documents/policies/ organized-crime-and-human-trafficking/corruption/docs/acr_2014_es.pdf)

3 No obstante, De la Cuesta pone de relieve las dificultades a las que se enfrenta la adecuada medición de la extensión de un fenómeno altamente dependiente de causas estructurales. DE LA CUESTA ARZAMENDI, J.L.: "La corrupción ante el Derecho y la justicia", en Diritto Penale Contemporaneo, 2014, p. 2, (http://www.penalecontemporaneo.it/upload/1388929330 DELACUESTA_2014a.pdf).

4 AGUADO CORREA, T.: "Decomiso de los productos de la delincuencia organizada. "Garantizar que el delito no resulte provechoso»", en Revista Electrónica de Ciencia Penal y Criminología, 15-05, 2013, pp. 8 y ss, (http://criminet.ugr.es/recpc); CAMPOS NAVAS, D.: "Comiso y medidas cautelares. Regulación vigente y reformas en tramitación", en Cuadernos Digitales de Formación, Consejo General del Poder Judicial, n 29, 2013, pp. 3 y ss; FARALDO CABANA, P.: "La regulación del comiso en España. Especial referencia a los comisos específicos en los delitos de tráfico de drogas, blanqueo de bienes y contrabando", en Revista Peruana de Ciencias Penales, $\mathrm{n}^{\circ}$ 20, 2008, (http://www.ecrim.es); y, SÁNCHEZ GARCÍA DE PAZ, I.: La criminalidad organizada. Aspectos penales, procesales, administrativos y policiales, Ministerio del Interior, Dykinson, Madrid, 2005, pp. 171 y ss. 
bién presididas por ese objetivo de enriquecimiento. El último eslabón de esta normativa lo constituye la Directiva 2014/42/UE del Parlamento Europeo y del Consejo de 3 de abril de 2014, sobre el embargo y el decomiso de los instrumentos y del producto del delito en la Unión Europea ${ }^{5}$. En ella se subraya la finalidad económica que motiva la delincuencia organizada transfronteriza y la necesidad de dotar a las autoridades nacionales de medios eficaces para requisar esos elementos. Pero, además, se manifiesta la conveniencia de permitir en algunas situaciones la recuperación de bienes no asociados al ilícito enjuiciado, sino procedentes de otros distintos, mediante la figura del "decomiso ampliado". Se considera preciso posibilitar el decomiso en ciertas circunstancias en las que no se puede condenar al acusado, como en caso de rebeldía o fallecimiento, así como el de bienes transferidos a terceros que conocían o debían prever su origen ilícito. También se dispone que cuando no sea posible privar del objeto original se debe asegurar el de un valor equivalente.

Pues bien, siguiendo esas directrices la Ley Orgánica 1/2015, de 30 de marzo, modificó sustancialmente la regulación del decomiso (en el articulado se usa ahora esta expresión, de acuerdo con la citada Directiva, en lugar del término anterior "comiso") y amplió notablemente su campo de aplicación. De hecho, el artículo $127 \mathrm{CP}$ se ha desdoblado en ocho preceptos distintos (los arts. 127 a 127 octies), además del artículo 128, que permite al juez no decretarlo o acordarlo sólo parcialmente, cuando considere que privar de un concreto bien sería desproporcionado. En esas nuevas normas se incrementa el uso de algunas modalidades controvertidas en nuestro Derecho, como el decomiso acordado sin condena, el de bienes de terceros, o el ampliado, que antes regía sólo para la criminalidad organizada y terrorista y ahora se extiende a una larga lista de delitos que suelen proporcionar importantes beneficios económicos. Entre

5 Respecto a los mecanismos preventivos previstos en las normas internacionales es de interés, DE LA CUESTA ARZAMENDI, J.L.: "Iniciativas internacionales contra la corrupción", en Eguzkilore, nº 17, 2003, pp. 11 y ss. 
ellos, la malversación y el cohecho, representativos de lo que comúnmente se conoce como "corrupción" ción en los negocios. Esto supone que cuando una persona sea condenada por alguna de estas infracciones se le podrán decomisar los bienes, efectos y ganancias procedentes de ese hecho, pero también otros que posea cuando haya indicios objetivos fundados de que provienen de una actividad delictiva previa y no se acredite su origen lícito.

Hay que decir que el Tribunal Constitucional ha admitido la prueba de indicios para el comiso ${ }^{7}$. Y ha señalado que el principio de presunción de inocencia deja de actuar una vez acreditada la culpabilidad del imputado, de modo que en la fase de concreción de las consecuencias, entre ellas el decomiso, ya no rige ese principio sino las demás garantías procesales y especialmente el derecho a la tutela judicial efectiva ${ }^{8}$.

6 En la regulación de estos ilícitos tiene una especial trascendencia la alarma social que generan, ALCÁZAR RAMOS, M.: "Corrupción política, Derechos fundamentales y opinión pública”, en JAREÑO LEAL, Á./DOVAL PAIS, A.: Corrupción pública, prueba y delito: cuestiones de libertad e intimidad, Aranzadi, Pamplona, 2015, p. 17. En particular, sobre el efecto de esa sensibilización social en la tipificación de la admisión de regalos por parte de los funcionarios, VÁZQUEZ-PORTOMEÑE SEIJAS, F.: "Admisión de regalos y corrupción pública. Consideraciones político criminales sobre el llamado "cohecho de facilitación» (art. $422 \mathrm{CP}$ )", en Revista de Derecho Penal y Criminología, $\mathrm{n}^{\circ}$ 6, 2011, pp. 153 y 154.

7 SSTC 219/2006, de 3 de julio (F.J.9), 220/2006, de 3 de julio (F.J.8), y 126/2011, de 18 de julio (F.J.14).

8 El Tribunal Constitucional ha declarado que este principio opera, "como el derecho del acusado a no sufrir una condena a menos que la culpabilidad haya quedado establecida más allá de toda duda razonable". "Una vez constatada la existencia de pruebas a partir de las cuales los órganos judiciales consideran razonadamente acreditada la culpabilidad del acusado, ya no está en cuestión el derecho a la presunción de inocencia. Por ello, en la acreditación de la concurrencia de los presupuestos para la imposición de una consecuencia accesoria como el comiso y en la imposición de la misma habrán de respetarse las garantías del proceso (art. 24.2 CE) y las exigencias del derecho a la tutela judicial efectiva (art. 24.1 CE)". STC 219/2006, de 28 de julio (F.J.9). 
No obstante, el Tribunal Supremo ha señalado que "el comiso, aunque no incluido en el catálogo de las penas contenido en el artículo $33 \mathrm{CP}$, constituye una sanción sometida a los principios de culpabilidad, proporcionalidad, pertinencia y legalidad". Además, recuerda que son muchas las resoluciones judiciales que lo desestiman por no estar los efectos relacionados con el delito, o no guardar la debida proporcionalidad con el hecho enjuiciado?

Pero, a mi juicio, es cuestionable que la nueva regulación del decomiso cumpla esas exigencias, puesto que algunas de las normas que permiten practicarlo se basan en presunciones de ilegalidad de los elementos confiscados, sin requerir siquiera la existencia de indicios objetivos fundados en cuanto a esa procedencia ilícita. Basta leer el contenido del artículo 127 sexies $\mathrm{CP}^{10}$, que en un principio se preveía en la Disposición Adicional Segunda del Anteproyecto de reforma de la Ley de Enjuiciamiento Criminal ${ }^{11}$, y se incorporó al Proyecto de Código penal ${ }^{12}$. Respecto a este

9 STS 1528/2002, de 20 de septiembre (F.J.2).

10 Artículo 127 sexies: "A los efectos de lo previsto en el artículo anterior serán de aplicación las siguientes presunciones: $1^{\circ}$. Se presumirá que todos los bienes adquiridos por el condenado dentro del período de tiempo que se inicia seis años antes de la fecha de apertura del procedimiento penal, proceden de su actividad delictiva. A estos efectos, se entiende que los bienes han sido adquiridos en la fecha más temprana en la que conste que el sujeto ha dispuesto de ellos. $2^{\circ}$. Se presumirá que todos los gastos realizados por el penado durante el periodo de tiempo a que se refiere el párrafo primero del número anterior, se pagaron con fondos procedentes de su actividad delictiva. $3^{\circ}$. Se presumirá que todos los bienes a que se refiere el número 1 fueron adquiridos libres de cargas. El juez o tribunal podrá acordar que las anteriores presunciones no sean aplicadas con relación a determinados bienes, efectos o ganancias, cuando, en las circunstancias concretas del caso, se revelen incorrectas o desproporcionadas".

11 Anteproyecto de Ley Orgánica de modificación de la Ley de Enjuiciamiento Criminal para el fortalecimiento de las garantías procesales y la regulación de las medidas de investigación tecnológica, aprobado por el Consejo de Ministros el 5 de diciembre de 2014.

12 Esta disposición se introdujo en el Proyecto de reforma del Código penal como consecuencia de una enmienda del Grupo Parlamentario Popular en el 
precepto, la Fiscalía General del Estado ya advirtió que "desvincula la apreciación indiciaria de alguna actividad delictiva concreta al introducir una serie de presunciones cuya aplicación puede llevar a la posibilidad de decretar el comiso ante cualquier enriquecimiento injustificado que resulte desproporcionado. Esto sí puede suponer una auténtica inversión de la carga de la prueba $y$, por tanto, la posible vulneración del principio de presunción de inocencia" ${ }^{\prime \prime}$.

Como decía, ese aumento tan significativo de la importancia y del uso del decomiso ha venido marcado por las normas comunitarias y particularmente por la Directiva 2014/42/ UE, que prevé la obligación de los estados miembros de adoptar las tres formas apuntadas en una serie de delitos que nuestro legislador amplía.

Sin embargo, en la nueva regulación también han ejercido una gran influencia otras legislaciones de nuestro entorno y sobre todo el Derecho alemán. De hecho, en la Exposición

Senado, que consideró apropiado aprovechar la modificación de este texto para incluir lo que en definitiva es Derecho sustantivo. Enmienda $\mathrm{n}^{\circ} 964$ del Grupo Parlamentario Popular en el Senado (GPP). Boletín Oficial de las Cortes Generales. Senado. X Legislatura. 23 de febrero de 2015, p. 675.

13 "Nada impide que las presunciones que se proponen por el prelegislador, en los supuestos concretos en que adquieran un carácter indiciario pueden ser apreciadas en cada caso por los Tribunales, pero otorgarles carácter legal puede llevar a excesos que el propio prelegislador reconoce al establecer en el párrafo final del artículo 127 sexies que el Juez o Tribunal podrá acordar que las anteriores presunciones no sean aplicadas con relación a determinados bienes, efectos o ganancias, cuando, en las circunstancias concretas del caso, se revelen incorrectas o desproporcionadas. En consecuencia y sin perjuicio de considerar acertada la decisión del legislador de ampliación de las posibilidades de decretar el comiso de bienes de procedencia delictiva, se estima imprescindible una regulación mucho más detallada, congruente y armónica con el sistema que se adopte respecto de la institución del comiso". Informe del Consejo Fiscal al Anteproyecto de Ley Orgánica de modificación de la Ley de Enjuiciamiento Criminal para la agilización de la justicia penal, el fortalecimiento de las garantías procesales y la regulación de las medidas de investigación tecnológicas, de 23 de enero de 2015, (http://pdfs.wke.es/2/2/7/8/pd0000102278.pdf), pp. 166 y 167. 
de Motivos de Ley Orgánica 1/2015, de 30 de marzo, se reproducen algunos párrafos de un Auto del Tribunal Constitucional alemán de 14 de enero de 2004, al que luego me referiré, en el que rechaza que el comiso sea una sanción penal y, por lo tanto, confirma la adecuación a la Ley Fundamental del ampliado. En realidad, el texto español no cita expresamente esa resolución, sino que alude a la "jurisprudencia constitucional comparada", pero afirma los mismos fines que el tribunal germano atribuyó al comiso en esa ocasión. Dice la Exposición de Motivos:

"La regulación, por lo demás, es, como se ha afirmado en la jurisprudencia constitucional comparada, ajustada a los principios de culpabilidad y presunción de inocencia, pues no persigue reprochar al condenado la realización de un hecho ilícito, lo que sería propio de una pena, sino conseguir fines ordenadores del patrimonio y de corrección de una situación patrimonial ilícita derivada de un enriquecimiento injusto de origen delictivo".

Curiosamente, esta fundamentación no figuraba en ninguna de las versiones del Anteproyecto de reforma del Código penal. En el texto original de 16 de julio de 2012, solo se modificaba el artículo 127 para suprimir la referencia a las faltas. Sin embargo, en la versión posterior de 11 de octubre de 2012 se introdujeron los artículos 127 bis a 127 sexies, a la vista de la Propuesta de Directiva de 12 de marzo de 2012, que se aprobaría dos años más tarde ${ }^{14}$. Pero en la Exposición de motivos no aparecían todavía esos argumentos. Fue en el Proyecto de reforma de 20 de septiembre de 2013 cuando ya se aludió tanto a la jurisprudencia del TEDH como a esa jurisprudencia constitucional comparada.

De todas formas, en la resolución del Tribunal Constitucional alemán se atribuye al decomiso tanto un fin de "orde-

14 AGUADO CORREA, T.: "Crónica de una reforma anunciada", en InDret, 1/2014, (www.indret.com), pp. 3 y ss; y, SILVA CASTAÑO, M.L.: "La nueva Directiva sobre el comiso", en Aranzadi Doctrinal, n 3, 2015, (https:// insignis.aranzadidigital.es). 
nación del patrimonio", como de "estabilización de la norma". En cambio, en la Exposición de Motivos de la ley española se afirma que es una institución "de naturaleza más bien civil y patrimonial, próxima a la de figuras como el enriquecimiento injusto". Además, se omite la segunda finalidad, que parece apuntar a la prevención general positiva propia de las sanciones penales. Por otra parte, no se dice que en el Derecho alemán junto al comiso (en ese ordenamiento se sigue empleando este término) se regula la confiscación, que priva de los productos e instrumentos del delito y en este caso sí se entiende que se trata de una pena. Es evidente que el legislador ha querido perfilar el decomiso como una respuesta no punitiva y atribuirle un carácter puramente económico. Bajo este fundamento extiende su aplicación a numerosos supuestos y flexibiliza los requisitos para acordarlo, recurriendo con frecuencia a presunciones legales respecto al origen ilícito de los bienes.

\section{Medidas contra la corrupción en Alemania}

Alemania cuenta con una amplia gama de medidas legales contra la corrupción, de manera que junto al Reino Unido son los dos países del mundo con más previsiones de esta índole, según un Informe de 2013 de la Organización para la Cooperación y el Desarrollo Económicos (OECD) ${ }^{15}$.

Aunque la percepción de los ciudadanos sobre los niveles de corrupción en su país no es elevada, en comparación con otros estados europeos, en los últimos años se han intensificado las respuestas penales contra estas conductas, siguiendo las recomendaciones comunitarias ${ }^{16}$. En el Informe de la Comisión

15 (http://www.oecd.org/daf/anti-bribery/antibriberyannrep2012.pdf).

16 De acuerdo con el «Índice de percepción de la corrupción» de Transparenty International del año 2015, Alemania obtuvo una de las puntuaciones más bajas en cuanto a la visión de este fenómeno que tienen los empresarios y analistas, situándose en el puesto 10 de un total de 167 países analizados. (http://ransparencia.org.es/wp-content/uploads/2016/01/tabla_sinteti- 
Europea sobre la lucha contra la corrupción de $2014^{17}$, se reconocía el esfuerzo de las autoridades alemanas para combatirla, pero se aconsejaba revisar la legislación en algunos aspectos ${ }^{18}$. Siguiendo estas indicaciones, recientemente se han aprobado varias leyes de reforma del Código penal (StGB) ${ }^{19}$, en las que se modifica el soborno a parlamentarios, se tipifica el producido en el tráfico comercial internacional, el relativo a funcionarios extranjeros y de organismos internacionales. Además, se han atendido las sugerencias que efectuó el Tribunal Supremo alemán (Bundesgerichtshof) en la sentencia de 29 de marzo de $2012^{20}$, creando tipos específicos de soborno en el ámbito sanitario, con lo que se zanja el problema que planteaba el encaje de estas conductas en los delitos de funcionarios cuando afectaban a médicos contratados.

Precisamente, característica de esa normativa es la regulación de delitos específicos de corrupción, que se encabezan bajo el título "Bestechung" (corrupción, soborno, o cohecho), o

ca_ipc-2015.pdf). No obstante, según el «Eurobarómetro» de 2013 de la Comisión Europea, que mide la opinión de la población en general, algo más de la mitad de los ciudadanos cree que la corrupción es un fenómeno extendido, aunque este porcentaje sigue siendo bajo si lo comparamos con el $95 \%$ de los encuestados en nuestro país que cree la corrupción es elevada (http://ec.europa.eu/dgs/home-affairs/e-library/documents/policies/ organized-crime-and-human-trafficking/corruption/docs/acr_2014_es.pdf).

17 Informe de la Comisión al Consejo y al Parlamento Europeo sobre la lucha contra la corrupción en la UE, de 3 de febrero de 2014, COM (2014) 38, p. 1, (http://ec.europa.eu/dgs/home-affairs/e-library/documents/policies/ organized-crime-and-human-trafficking/corruption/docs/acr_2014_es.pdf).

18 (http://www.ventanaeuropea.es/Blog/index.php/euronoticias/reforma-dela-legislacion-para-prevenir-la-corrupcion-parlamentaria/).

19 La Ley de 23 de abril de 2014 sobre la extensión del delito de soborno de parlamentarios (Strafrechtsänderungsgesetz-Erweiterung des Straftatbestandes der Abgeordnetenbestechung), la Ley para combatir la corrupción de 20 de noviembre de 2015 (Gesetz zur Bekämpfung der Korruption), y la Ley para combatir la corrupción en el ámbito de la salud de 30 de mayo de 2016 (Gesetz zur Bekämpfung von Korruption im Gesundheitswesen).

20 (BGH - Beschluss Az. GSSt 2/11), (http://openjur.de/u/428459.html ). 
"Bestechlichkeit" (corruptibilidad) ${ }^{21}$. No obstante, estos ilícitos no se encuadran en un apartado específico sino que se distribuyen en títulos distintos, según afecten a los parlamentarios o representantes populares, al tráfico comercial, o a funcionarios ${ }^{22}$. En todos ellos el elemento común es el soborno, de modo que hay un abuso de poder para obtener una ventaja indebida ${ }^{23}, y$ el sujeto activo es siempre una persona física ${ }^{24}$, puesto que en

21 Por ejemplo, Kindhäuser trata los presupuestos de la corrupción punible, e indica que los tipos penales de la corrupción económica (cohecho en el ámbito comercial) han copiado los de cohecho pasivo y activo en el ámbito estatal con casi idéntico tenor literal. KINDHÄUSER, U.: "Presupuestos de la corrupción punible en el estado, la economía y la sociedad. Los delitos de corrupción en el Código penal alemán", en Política Criminal, vol. 2, nº 3 , 2007, p. 4, (http://www.politicacriminal.cl/n_03/a_1_3.pdf).

22 En el Título 4. «Delitos contra los órganos constitucionales así como en las elecciones y consultas», el artículo 108 e prevé la "Corruptibilidad y soborno del parlamentario". En el Título 26. «Delitos contra la competencia», el artículo 298 penaliza los “Acuerdos para limitar la competencia en las licitaciones", y los artículos 299, 299 a y 299 b, la "Corruptibilidad y soborno en el tráfico comercial". Y en el Título 30. «Delitos de funcionarios en el ejercicio del cargo», los artículos 331 a 335 se dedican a la "Aceptación de ventaja", "Cohecho pasivo", "Otorgamiento de ventaja" y "Cohecho activo". Sobre estas normas, KINDHÄUSER, U.: "Presupuestos de la corrupción punible...", cit., pp. 1 y ss; y, SATGER, H./SCHMITT, B./WIDMAIER, W.: Strafgesetzbuch Kommentar, Carl Heymann Verlag, München, 2009, pp. 1966 y ss.

23 ENGERER, U.: Folgen und Bekämpfung von Korruption: liefern ökonomische Ansätze bestechende Argumente?, en Diskussionspapiere, Deutsches Institut für Wirtschaftsforschung, $\mathrm{n}^{\circ}$ 161, 1998, p. 1, (https://www. diw.de/documents/publikationen/73/diw_01.c.38637.de/dp161.pdf); KINDHÄUSER, u: "Presupuestos de la corrupción...", cit., p. 6; y, WOLF, S.: "Die Modernisierung des deutschen Antikorruptionsstrafrechts durch internationale Vorgaben. Momentaufnahme und Ausblick", Neue Juristische Wochenschrift, vol. 59, no 38, 2006, pp. 2735 y ss.

24 En este ordenamiento se parte de la teoría del "deber del cargo" y se fundamenta el injusto de los delitos de funcionarios en la infracción del deber específico de su función. DE LA MATA BARRANCO, N.J.: “¿Qué interés lesionan las conductas de corrupción?", en Eguzkilore, n 23, 2009, p. 247, (http://www.ehu.eus/documents/1736829/2176697/19-De+la+Mata.indd. pdf). 
Alemania las personas jurídicas no son sancionadas penalmente sino conforme al Derecho administrativo ${ }^{25}$.

Pues bien, junto a esos ilícitos concretos en el ordenamiento alemán se atribuye mucha importancia al comiso como medida preventiva, pero también como una vía de restablecer el equilibrio patrimonial injustamente alterado por el delito. Esta concepción explica que figuras como el comiso sin condena ${ }^{26}$, el de bienes de terceros y el ampliado cuenten con una larga tradición jurídica. En concreto, La "Ley para combatir el tráfico ilegal de estupefacientes y otras formas de aparición de la criminalidad organizada", de 15 de julio de 1992 (Gesetz zur Bekämpfung des illegalen Rauschgifthandels und anderer Erscheinungsformen der Organisierten Kriminalität -OrgKG-), introdujo el $\S 73 \mathrm{~d}$ StGB, donde se regula el comiso ampliado ${ }^{27}$. Posteriormente, la "Ley para la lucha contra la corrupción", de 13 de agosto de 1997 (Gesetz zur Bekämpfung der Korruption), lo extendió al delito de cohecho ( $\$ 368$ StGB). Con estas nuevas normas se pretendía unificar las sanciones relativas a los delitos contra la propiedad, hasta entonces dispersas, pero sobre todo potenciar el uso de la medida de comiso, que se consideraba insuficientemente utilizada ${ }^{28}$.

25 BACIGALUPO, S./LIZCANO, J.: Responsabilidad penal y administrativa de las personas jurídicas en delitos relacionados con la corrupción, Colección Estudios, $n^{\circ}$ 1, Eurosocial, Madrid, 2013, pp. 44 y ss, (http://sia. eurosocial-ii.eu/files/docs/1400660079-E1.pdf).

26 La modalidad ahora prevista en el artículo 127 ter $\mathrm{CP}$ ha recibido diversas denominaciones, en el ámbito internacional se impone la de "comiso sin condena". BLANCO CORDERO, I.: "Recuperación de activos de la corrupción mediante el decomiso sin condena (comiso civil o extinción de dominio)", en FABIÁN CAPARRÓS, E.A./ONTIVEROS ALONSO, M./ RODRÍGUEZ GARCÍA, N. (Ed.): El Derecho penal y la política criminal frente a la corrupción, Ibijus, México, 2012, p. 339.

27 SCHÖNKE, A./SCHRÖDER, H.: Strafgesetzbuch Kommentar, 28 Auflage, Verlag. C.H.Beck München, 2014, p. 575.

28 TRÖNDLE. H./FISCHER, T.: Strafgesetzbuch und Nebengesetze, C.H.Beck'sche Verlagsbuchhandlung, München, 2006, p. 1112. 
Por otra parte, en la jurisprudencia se ha elaborado toda una doctrina en cuanto al contenido que debe abarcar el comiso, que en nuestro sistema resulta llamativa. Como después se verá, tanto el Tribunal Constitucional como el Tribunal Supremo en diversas sentencias dedican buena parte de su fundamentación a delimitar el alcance que debe tener esta consecuencia y, específicamente, a precisar si ha de abarcar el llamado beneficio bruto o si se tienen que detraer los costes y requisar tan solo el beneficio neto.

Pues bien, como he apuntado, en ese Derecho se diferencian dos medidas distintas, aunque estrechamente ligadas. En primer lugar, el comiso (Verfall), que despoja de las ventajas patrimoniales obtenidas por el delito o derivadas del mismo, y, en segundo lugar, la confiscación (Einziehung), que priva de los objetos producto del delito o que han sido empleados en su preparación o ejecución, o destinados a este fin. La relevancia de estas consecuencias ha llevado a perfilar su distinta naturaleza, contraponiendo la primera, que según el Tribunal Constitucional no es una pena ni una sanción asimilada a ella, y la confiscación que sí reviste ese carácter punitivo.

\section{Comiso básico}

El comiso se regula en los $\S \S 73$ a 73 e StGB, dedicándose al denominado "ampliado" el § 73 d, al que luego me referiré. En cuanto a su naturaleza jurídica, tanto el Tribunal Constitucional alemán como el Tribunal Supremo han coincidido en que no es una pena ni una medida de seguridad, puesto que no está vinculado a la culpabilidad ${ }^{29}$. Se trata de una medida sui generi ${ }^{30}$, que consistente en requisar las ganancias patrimoniales obtenidas

29 (BVerfGE 110, 1 (14 ss), (BGHSt 47, 260 (265). KINDHÄUSER, U.: Strafgesetzbuch. Lehr- und Praxiskommentar, 5 Auflage, Nomos, Baden-Baden, 2013, p. 463.

30 FISCHER, T.: Strafgesetzbuch und Nebengesetze, 59 Auflage, Verlag. C.H.Beck München, 2012, p. 680; y, SCHÖNKE, A./SCHRÖDER, H.: Strafgesetzbuch Kommentar, cit., p. 565. 
ilegalmente con un fin preventivo ${ }^{31}$, en tanto la realización de un delito no debe suponer un beneficio para su autor o partícipe, ni para los terceros amparados por ellos ${ }^{32}$. De todas formas, su regulación ha sufrido modificaciones importantes que han repercutido en el contenido de esta figura.

\subsection{Regulación}

\section{$\S 73$ StGB. Presupuestos del comiso}

1. Si se ha cometido un acto antijurídico y el autor o partícipe ha obtenido algo para sí por el hecho o derivado del mismo, el tribunal ordenará su comiso. Esto no se aplica en casos en que el perjudicado obtiene un derecho del hecho ilícito, cuyo cumplimiento supone que se prive al autor o participe de ese beneficio.

2. La orden de decomiso se extiende a las ganancias obtenidas. También puede extenderse a los objetos adquiridos por el autor o el participe tras la venta del objeto ilícitamente adquirido o como sustitución del mismo, por su destrucción, daño o confiscación o en virtud de un derecho adquirido.

3. Si el autor o el partícipe ha actuado para otro y ha conseguido algo para él, entonces se expide la orden de comiso contra él de acuerdo con el inciso primero.

4. El comiso del objeto también procede cuando pertenece a un tercero que lo recibió con conocimiento de las circunstancias del hecho ilícito.

\section{$\S 73$ a StGB}

Cuando el comiso de un objeto determinado no sea posible a causa de la naturaleza de lo obtenido o por otra razón, o el comiso de un objeto sustitutivo no sea posible conforme al $\S$ 73 apartado 2 frase 2, el Tribunal impondrá el comiso de una cantidad económica, que se corresponda con el valor de lo obtenido. El Tribunal también hará uso de esta posibilidad, junto

31 (BGHSt 31, 145; NJW 02, 2257 y 3339). KÜHL, K.: Strafgesetzbuch Kommentar, 27 Auflage, Verlag. C.H.Beck, München, 2011, p. 528.

32 (BVerfG 110, 1 ss), (BGHSt 47, 369 [373 ss]). KINDHÄUSER, U.: Strafgesetzbuch. Lehr- und Praxiskommentar, cit., p. 463. 
al comiso de un objeto, cuando el valor de éste sea inferior al valor del objeto originalmente obtenido.

\section{$\S 73 \mathrm{~b} \mathrm{StGB}$}

La extensión de lo adquirido y su valor, así como el importe en que se tase el derecho afectado, son extremos que pueden ser determinados, pudiendo reclamarse el pago de esas cantidades al autor o a su partícipe.

\section{$\S 73 \mathrm{c} \mathrm{StGB}$}

1. La medida de comiso no será acordada cuando sea desproporcionada para el afectado. La medida de comiso podrá omitirse cuando el valor de lo obtenido ya no esté presente en su patrimonio o cuando se trate de un valor escaso.

2. Para la concesión de facilidades de pago rige el $\$ 42$ en lo pertinente.

Como se desprende del $\S 73$ StGB el comiso se debe acordar con carácter preceptivo siempre que se realiza un acto antijurídico, aunque no sea culpable ni se imponga una pena ${ }^{33}$. Aquí se advierte una primera diferencia respecto a nuestro ordenamiento, donde el artículo 127 ter CP prevé el decomiso sin sentencia condenatoria con carácter facultativo y sólo en ciertos supuestos ${ }^{34}$. No

33 KÜHL, K.: Strafgesetzbuch Kommentar, cit., p. 528; SCHÖNKE, A./ SCHRÖDER, H.: Strafgesetzbuch Kommentar, cit., p. 566; y, TRÖNDLE.H./ FISCHER, T.: Strafgesetzbuch und Nebengesetze, cit., p. 1117.

34 Fallecimiento, enfermedad crónica, rebeldía, exención o extinción de la responsabilidad penal, siempre que el afectado hubiera sido acusado o imputado en el procedimiento y quede acreditada la situación patrimonial ilícita. Puente Aba matiza que, no obstante, el precepto español va más allá que las disposiciones alemanas puesto que, al permitir la aplicación del comiso en cualquier caso de exención de responsabilidad penal, se podría decretar en supuestos de comisión de actos que ni siquiera resultan antijurídicos por concurrencia de una causa de justificación, mientras que el Código penal alemán exige que la acción sea al menos antijurídica. PUENTE ABA, L.M.: "La regulación del comiso en el Código penal español", Centro de Investigación Interdisciplinaria en Derecho Penal Económico, Córdoba, Argentina, 2009, p. 8, (www.ciidpe.com.ar). 
obstante, según la norma alemana no se aplica si el perjudicado tiene derecho al beneficio, por ejemplo, mediante la restitución del objeto por vía de la responsabilidad civil. Además, se contempla la posibilidad de que el autor o partícipe hayan actuado para otro, que puede ser una persona física o jurídica, e incluso una asociación sin capacidad jurídica ${ }^{35}$. En este caso, como se verá, la jurisprudencia niega el comiso cuando se trata de un tercero de buena fe. Asimismo, si el objeto del delito pertenece a un tercero sólo se puede decomisar si conocía su procedencia ilícita. Por el contrario, el nuevo artículo 127 quáter $\mathrm{CP}$ no precisa que el tercero sepa que el bien es ilegal, sino que para quitárselo basta que una persona diligente hubiera tenido motivos para sospechar ese origen ilícito.

Además, el $\S 73$ a StGB dispone que cuando no sea posible el decomiso o el objeto hubiera perdido valor el tribunal debe imponer una cantidad económica equivalente y a estos efectos el $\S 73$ b StGB contempla la tasación del objeto. No obstante, de acuerdo con este precepto ese pago sustitutivo se limita únicamente a los autores y partícipes. Por el contrario, en nuestro Derecho el artículo 127 quáter $\mathrm{CP}^{36}$ establece la posibi-

35 RHODE, M.: "El comiso según el art. 73. $3^{\circ}$ StGB", en WISTRA, $\mathrm{n}^{\circ}$ 3, 2012, p. 85, (https://beck-online.beck.de/?vpath=bibdata\%2Fzeits\%2FWISTRA $\% 2 \mathrm{~F} 2012 \% 2 \mathrm{Fcont} \% 2 \mathrm{FWISTRA} \% 2 \mathrm{E} 2012 \% 2 \mathrm{Ehtm}$ ).

36 Artículo 127 quáter CP: “1. Los jueces y tribunales podrán acordar también el decomiso de los bienes, efectos y ganancias a que se refieren los artículos anteriores que hayan sido transferidos a terceras personas, o de un valor equivalente a los mismos, en los siguientes casos: a) En el caso de los efectos y ganancias, cuando los hubieran adquirido con conocimiento de que proceden de una actividad ilícita o cuando una persona diligente habría tenido motivos para sospechar, en las circunstancias del caso, de su origen ilícito. b) En el caso de otros bienes, cuando los hubieran adquirido con conocimiento de que de este modo se dificultaba su decomiso o cuando una persona diligente habría tenido motivos para sospechar, en las circunstancias del caso, que de ese modo se dificultaba su decomiso. 2. Se presumirá, salvo prueba en contrario, que el tercero ha conocido o ha tenido motivos para sospechar que se trataba de bienes procedentes de una actividad ilícita o que eran transferidos para evitar su decomiso, cuando los bienes o efectos le hubieran sido transferidos a título gratuito o por un precio inferior al real de mercado". 
lidad de exigirlo a los terceros adquirentes. El contraste con el Derecho alemán pone de relieve la inconsistencia de esta previsión e incluso su legitimidad plantea dudas desde el punto de vista constitucional. Por una parte, porque no se requiere que el tercero efectivamente conociera el origen ilícito del bien, bastando que una persona diligente lo hubiera podido prever. Aunque en el fondo se está pensando en el testaferro que contribuye conscientemente a ocultar el objeto delictivo, y se establece esa presunción por la dificultad de acreditar esta intención, no se puede descartar que en algún caso el comprador no se haya planteado que se trata de un objeto sustraído, sobre todo si el precio pagado no es muy inferior al de mercado (puede pensar, por ejemplo, que el coste menor responde a la adquisición de una partida grande por el vendedor). Además, la norma española permite decomisar una cuantía sustitutiva al adquirente, aunque haya regalado el bien sin obtener a cambio ningún beneficio. Por tanto, el fundamento del enriquecimiento ilícito que se aduce en el Derecho alemán en este caso no sirve, sino que parece más bien una sanción impuesta a una persona no responsable del delito, presumiendo que en el fondo conocía su procedencia ilegal.

Por otra parte, el $\S 73$ c StGB afirma el principio de proporcionalidad con carácter imperativo ${ }^{37}$, a diferencia del artículo $128 \mathrm{CP}$ que permite al juez o tribunal no decretar el decomiso o acordarlo sólo en parte. No obstante, el Tribunal Supremo afirma que rige en todo caso.

\subsection{El "Principio bruto" (Bruttoprinzip)}

El § 73 StGB dispone que si el autor o partícipe ha obtenido "algo" (etwas) para sí por el hecho o derivado del mismo el tribunal decretará el comiso. Esa expresión incluye toda ventaja patrimonial, tanto cosas, como derechos reales, e incluso una

37 AGUADO CORREA, T.: "La Directiva 2014/42/UE sobre embargo y decomiso en la Unión Europea: una solución de compromiso a medio camino", en Revista General de Derecho Europeo, n 35, 2015, p. 32, (www.iustel. com). 
facultad de uso ${ }^{38}$. Además, la orden abarca las ganancias obtenidas y puede extenderse a los objetos adquiridos tras la venta del objeto delictivo o como sustitución del mismo, en caso de destrucción, daño o confiscación o en virtud de un derecho adquirido. Las ganancias incluyen sólo las derivadas directamente del delito, aunque se hayan invertido en la adquisición de bienes y comprenden los beneficios de su explotación. Igualmente, se permite privar de aquello que se ha obtenido con el dinero de la venta del objeto ilícito, así como los derechos surgidos por su daño o destrucción, por ejemplo, frente a la compañía de seguros y el responsable civil en caso de sufrir un accidente el vehículo sustraído ${ }^{39}$. Nuestro Código contiene una disposición semejante, ordenando decomisar las ganancias cualesquiera que sean las transformaciones que hubieran experimentado. Además, el artículo 127 septies recoge una cláusula de cierre, disponiendo que cuando no sea posible el decomiso, el juez podrá acordar el de otros bienes incluso lícitos por un valor equivalente.

Pues bien, el punto espinoso de esta normativa es el término "algo" (etwas) que integra el objeto del comiso. Originariamente, el $\S 73$ apartado 1 StGB se refería a la "ganancia patrimonial" (Vermogensvörteil) ${ }^{40}$. Esta cláusula se interpretó doctrinal y jurisprudencialmente como una referencia al denominado "beneficio neto" o "principio neto" (Nettoprinzip). Esto suponía que se debía decomisar sólo la ganancia final del delito descontando los gastos que se hubieran realizado en la ejecu-

38 KÜHL, K.: Strafgesetzbuch Kommentar, cit., p. 528; y, SCHÖNKE, A./ SCHRÖDER, H.: Strafgesetzbuch Kommentar, cit., p. 568.

39 KINDHÄUSER, U.: Strafgesetzbuch. Lehr- und Praxiskommentar, cit., p. 464.

40 El origen de esta expresión se sitúa en el Proyecto Alternativo alemán, MANZANARES SAMANIEGO, J.L.: "Aproximación al comiso del nuevo artículo 344 bis e) del Código penal (Ley Orgánica 1/1988, de 24 de marzo, de reforma del Código penal en materia de tráfico ilegal de drogas. «B.O.E.» de 26 del mismo mes)", en Boletín de Información. Ministerio de Justicia e Interior, $\mathrm{n}^{\mathrm{o}} 1500$ a 1502, 1988, p. 3798, (http://www.mjusticia.gob.es). 
ción ${ }^{41}$. Sin embargo, la Ley de 28 de febrero de 1992 (Gesetz zur Änderung des Außenwirtschaftsgesetzes, des Strafgesetzbuches und anderer Gesetze $)^{42}$ sustituyó esa expresión por el término "algo" (etwas). A partir de entonces empezó a aplicarse el "principio bruto" (Bruttoprinzip), privando de todo lo adquirido con el hecho ilícito sin restar los costes ${ }^{43}$.

No obstante, esta interpretación ha sido censurada por algunos autores porque entienden que privar de un valor superior al procedente de la infracción atribuye a esta medida un carácter de pena ${ }^{44}$. Sin embargo, tanto el Tribunal Constitucional como el Tribunal Supremo han mantenido esa interpretación, considerando que al practicar el comiso no se ha de restar lo invertido para conseguir el beneficio ${ }^{45}$. Esta postura se aprecia en diversas sentencias que se incluyen en los apartados siguientes.

41 SUCHY, O.: Der Verfall im Ordnungswidrigkeitenrecht. Eine Untersuchung ausgewählter Gesichtspunkte im wirtschaftsstrafrechtlichen Kontext, Herbert Utz, München, 2014, pp. 48 y ss.

42 (ttps://www.bgbl.de/xaver/bgbl/start.xav\#_bgbl_ $\% 2 \mathrm{~F} \% 2 \mathrm{~F} * \% 5 \mathrm{~B} \% 40$ attr_ id\%3D\%27bgbl192s0372.pdf\%27\%5D__ 1497529651193).

43 FISCHER, T.: Strafgesetzbuch und Nebengesetze, cit., p. 680; KÜHL, K.: Strafgesetzbuch Kommentar, cit., p. 528; y, SCHÖNKE, A./SCHRÖDER, H.: Strafgesetzbuch Kommentar, cit., p. 567.

44 Sobre el tema, FISCHER, T.: Strafgesetzbuch und Nebengesetze, cit., p. 682; SUCHY, O.: Der Verfall im Ordnungswidrigkeitenrecht..., cit., pp. 49 y 50; y, TRÖNDLE, H./FISCHER, T.: Strafgesetzbuch und Nebengesetze, cit., p. 1117.

45 En favor del principio bruto se han aducido razones de prevención general, puesto que optar por las ganancias netas supondría asegurarle al delincuente que va a recuperar lo invertido en la comisión del delito. Además, se ralentizaría la justicia, obligando a los jueces a hacer difíciles cálculos con el fin de garantizar que el culpable no pierda lo que gastó. Por otra parte, se dice que el beneficio no le pertenece al delincuente, pues el delito no es un título legítimo para la adquisición de la propiedad o de otros derechos sobre un bien. BLANCO CORDERO, I.: "El decomiso de las ganancias de la corrupción", en Revista Eletrônica de Direito Penal, vol. 1, n 1, 2013, pp. 116 y 117. Sobre la problemática que plantea la delimitación, ACQUAROLI, R.: "La fiscalidad de los sobornos", en ARROYO ZAPATERO, L./NIETO MARTÍN, A.: Fraude y corrupción en el Derecho penal europeo, Eurodelitos de corrupción y fraude, Ediciones de la Universidad de Castilla-La Mancha, Cuenca, 2016, pp. 355 y ss. 


\subsection{Particularidades en el delito de cohecho}

Como he apuntado, en Alemania hay tipos específicos de corrupción, y en ellos se utiliza el término "Bestechung", que se traduce indistintamente como soborno, cohecho, o corrupción, y el de "Bestechlichkeit" o corruptibilidad. De manera que las conductas de corrupción se identifican con las que implican soborno, asimilándose en el ámbito público al delito de cohecho de nuestro ordenamiento. Junto a ellas se regulan las producidas en el tráfico comercial y en el ámbito sanitario.

Pues bien, en ese país hay una jurisprudencia específica en el caso de las adjudicaciones ilegales constitutivas de cohecho. En estos supuestos, el Tribunal Supremo ha precisado que el objeto del comiso no es sólo el precio acordado por la concesión, sino que engloba: a) Las ganancias esperadas. Un indicio especialmente fuerte de ellas es el margen de beneficio que ha influido en el corruptor a la hora de proceder al cálculo del precio de la adjudicación (normalmente un porcentaje del mismo). Además, sirven como referencia las ganancias previsibles normalmente en la rama o sector de que se trate. b) En algunos casos pueden existir indicios de ventajas económicas adicionales de la adjudicación, por ejemplo, la posibilidad concreta de firmar posteriores contratos de mantenimiento de lo construido, o de obtener adjudicaciones de edificaciones similares, el aumento del valor económico del nombre comercial de la empresa por conseguir una concesión prestigiosa, la mejora de la posición de mercado mediante la eliminación de competidores, etc. Un indicio importante para la determinación de tal valor es el precio que está dispuesto a pagar el corruptor al sobornado ${ }^{46}$.

Esta interpretación se aparta de la mantenida en nuestra práctica judicial, donde se decomisan las ganancias y bienes obtenidos, pero en ningún caso los beneficios futuros.

46 Estas declaraciones corresponden a la sentencia del Tribunal Supremo alemán de 2 de diciembre de 2005. Extensamente, BLANCO CORDERO, I.: "La aplicación del comiso en caso de adjudicación de contratos públicos obtenida mediante soborno de funcionarios públicos", en Estudios Penales y Criminológicos, $\mathrm{n}^{\mathrm{o}} 27,2007$, pp. 54 y ss. 


\section{a) Sentencia del Tribunal Supremo de 21 de marzo de $2002^{47}$}

En este caso, se recurre ante el Tribunal Supremo una sentencia del tribunal regional de Hildesheim de 15 de junio de 2000. Se anula la parte de la sentencia relativa al comiso impuesto a uno de los dos acusados, $J$, de modo que se remitirá la causa a una sala diferente del tribunal regional para que realice un nuevo juicio y dicte sentencia, pudiendo aminorar la cantidad impuesta como comiso a J.

\section{ANTECEDENTES}

El tribunal regional condenó al acusado S por "corruptibilidad" en tres casos, "aceptación de beneficios" en dos y una por "defraudación de impuestos", a una pena total de tres años y seis meses de prisión. Al acusado J se le declaró culpable de "soborno" y se le impuso una pena de prisión de un año y seis meses, que quedó suspendida. Además, fue condenado por "defraudación de impuestos" a una pena de multa de cien dias. También se acordó el comiso contra ambos, de una cantidad compensatoria (Wertersatz), que fue fijada, para el acusado $S$, en un importe de 220.000 marcos alemanes y para el acusado $J$ en 6.575.000 marcos alemanes.

Ambos acusados interponen recurso contra la sentencia. La fiscalía..., recurre el fallo del acusado J, por estimar que el comiso acordado contra él es insuficiente.

El recurso planteado por el acusado J y la revisión de la fiscalía se dirigen, por tanto, a obtener la anulación de la sentencia que acuerda ese comiso.

\section{FUNDAMENTOS}

I. Según la declaración de hechos probados del tribunal regional, el acusado S, que fue hasta 1995 concejal de obras del ayuntamiento de Hemmingen y luego concejal de servicios sociales y orden público, obtuvo diversos sobornos gracias a su cargo...

El acusado $S$ ocultó en su declaración de impuestos..., la cantidad de 225.000 marcos. Por eso, redujo la cuantía que debía pagar aproximadamente en 70.000 marcos.

47 (BGHSt 47, 260), (openjur.de/u/61275.html). 
El acusado J. declaró unos gastos inexistentes en el ejercicio de 1995. De ese modo, alegó una deducción de 23.000 marcos de modo incorrecto, y evitó pagar la cantidad de 7.430 marcos.

El tribunal regional ordenó el comiso al acusado $S$ de una suma compensatoria, por los sobornos recibidos, que cifró en 220.000 marcos. Se le ha practicado una rebaja de 25.000 marcos, según el $\$ 73$ c párrafo 1 frase $2 S t G B$, porque esa suma ya no se encontró en el patrimonio de S. En cuanto al acusado $J$. se ha acordado el comiso de una cantidad compensatoria de cerca de 6.575.000 marcos. Se ha determinado esta elevada cuantía atendiendo al precio de venta de unos terrenos, que no eran urbanos y fueron declarados urbanizables, tras deducir su coste.

II. Se solicita la anulación de la sentencia en cuanto al comiso.

$1^{\circ}$. La revisión de la sentencia respecto del comiso impuesto al acusado $S$, que no se ha podido ejecutar, permite ver la corrección jurídica de ese apartado.

El tribunal ha determinado que $S$ recibió sobornos, existiendo un acuerdo injusto que se dirigía a una acción ilicita.

La sala ha razonado que las decisiones de urbanización tomadas (permisos de planificación y plan de desarrollo) fueron materialmente antijurídicas. A continuación, ha encajado lo sucedido en el delito de corruptibilidad del $\$ 332$ StGB.

Respecto a la orden de comiso al acusado $S$, al que se impone el pago de una suma compensatoria de 220.000 marcos, parece una decisión correcta. El tribunal ha examinado los presupuestos del $\$ 73$ c StGB de modo adecuado.

$2^{\circ}$. La revisión del acusado J. se dirige al comiso impuesto. No se admiten sus razonamientos...

El tribunal ha realizado una valoración eventual de los impuestos que se debian pagar por esos ingresos. Rechaza el argumento de que el comiso supone una dificultad para poder afrontar el pago de impuestos. Eso no es cierto, de modo general.

Para fijar la cuantía compensatoria cuyo comiso se acuer$d a$, el tribunal puede valorar las causas recogidas en las normas tributarias que permiten reducir el pago de impuestos. La autoridad tributaria ha negado que el comiso del $\$ 73$ apartado 
1 frase 1 StGB tenga carácter penal y permite de modo general aplicar tales deducciones (BFGH 192, 64, 71)...

La introducción del principio bruto por ley de 1992 modificó sólo la manera de calcular el comiso, pero dejó inalterada su naturaleza jurídica (BGH NJW 1995, 2235).

En consecuencia, la nueva regulación no modifica el principio básico de que el comiso no tiene finalidad penal, pues sirve únicamente para quitar al responsable la ventaja obtenida por el crimen.

Sobre esta base, el Tribunal Supremo ha afirmado que la imposición de una pena y de un comiso en la misma sentencia deben considerarse aspectos independientes, sin interrelación interna, y sin tener influencia uno en el otro (BGH NStZ 2001, 312; 2000, 137; vgl. auch BGHR StGB § 73d Strafzumessung 1).

Por tanto..., la cantidad impuesta como comiso y la pena concreta deben separarse y pueden ser objeto de recurso de modo separado, por motivos independientes.

$3^{\circ}$. El recurso interpuesto por la fiscalía también se desestima, en cuanto que reclama la imposición de una cantidad compensatoria más elevada al acusado $J . .$.

A) Frente a la petición de la fiscalía que exigía al tribunal regional la imposición a J. de una cuantía más elevada..., lo cierto es que el tribunal regional realizó una interpretación correcta del § 73 apartado 1 frase 1 StGB. Conforme a ese precepto, se supedita el comiso de los efectos a que el delincuente los poseyera para cometer el delito, o los haya obtenido gracias al delito. Por tanto, es decisivo determinar el valor económico de la ventaja que el autor obtuvo como consecuencia de su conducta ilícita (BGHR StGB § 73. $1^{\circ}$ ). El gravamen debe ser, por tanto, proporcionado a la ventaja patrimonial obtenida. Esto presupone una relación directa entre el acto y la ventaja. De ahi el uso de la expresión "algo" en el precepto... Renunciar a ese requisito sería intolerable y contrario al principio de seguridad jurídica.

B) El acusado J. no ha adquirido de modo inmediato el precio final de venta de los terrenos recalificados. La intervención que ha tenido en los hechos no se limita a sobornar a S. y a recibir 13 millones, precio de venta de los terrenos recalificados, pues tuvo que comprar un terreno y luego lo revendió por ese precio. Por ello el tribunal regional no admitió la petición de 
la fiscalía, que reclamaba que se decretara frente a J. el comiso de 13 millones de marcos, que fue el precio de venta final de los terrenos una vez se habia modificado su calificación urbanística. La referencia de la fiscalía a la ley de 1992 que introduce el "Bruttoprinzip" no es convincente. Este principio supone que el valor compensatorio que se fije como cantidad a decomisar, tomado en "bruto", no admite ninguna reducción. Sin embargo, este principio no es aplicable para resolver la cuestión de qué ventaja ha obtenido el condenado. La determinación de la ventaja precede, lógicamente, a la determinación de su extensión (y aqui es donde rige el "Bruttoprinzip").

C) El acusado J. logró, gracias al pago de sobornos, que el plan de desarrollo urbanístico "Arnum 31 C" entrara en vigor en partes relevantes. Había adquirido los terrenos entonces a precio claramente barato, como suelo no urbanizable, con la esperanza de que se recalificaran como urbanizables, y la posibilidad de obtener una ganancia se elevó decisivamente con esa especulación. Su ventaja se encuentra, por ello, en la posibilidad de alcanzar una considerable ganancia especulativa. Esta posible ganancia configura el "algo" que el acusado ha conseguido en el sentido del $\S 73$ apartado $1^{\circ}$ frase 1 StGB. Dado que el acusado J. llegó a realizar esa posibilidad de ganancia, el tribunal regional debería considerar que esa ganancia especulativa es la ventaja, en el sentido del $\$ 73$ apartado $1^{\circ}$ frase $1 \mathrm{StGB}$.

D) Para determinar la ganancia especulativa que obtuvo J., el tribunal regional ha tomado el precio de venta final -13 millones de marcos-y le ha deducido, conforme a Derecho, el precio de coste de los terrenos, y también los gastos asociados inevitablemente a la compra y la ulterior venta (impuestos y gastos de registro y notaría). Además, se han deducido de esa cantidad los costes de desarrollo del proyecto, que asumió J., porque... incrementó de modo evidente su valor, y este aumento no tiene conexión causal con el soborno. Del mismo modo, el tribunal regional no toma en cuenta los gastos de financiación de la compra para reducir la cantidad impuesta. En este sentido, se estimó que eran gastos personales del acusado $J$. (necesarios para posibilitar la especulación) que según el "Bruttoprinzip" debian quedar fuera de consideración. Pero estos gastos podrían en todo caso, -en este momento no se dan 
los presupuestos necesarios- ser valorados por el tribunal para reducir la cantidad que se fije como comiso, en el marco del $\$$ 73 c StGB, por lo que se anula la sentencia en ese apartado y se resolverá al respecto por otra sala del tribunal regional.

\section{b) Reflexiones personales}

El Tribunal Supremo declara, efectivamente, la vigencia del principio bruto respecto del comiso. Ahora bien, de acuerdo con la interpretación que efectúa esa regla se debe aplicar una vez calculada la ventaja derivada del delito y esto a veces requiere descontar los gastos realizados para obtenerla. En el caso del cohecho consistente en recalificar un terreno mediante el pago de un soborno a un funcionario, el beneficio consiste en el incremento del valor del inmueble que no era edificable y pasa a serlo a través del delito. Habría que concretar, pues, cuánto ha aumentado su precio al ser calificado como urbanizable. Por lo tanto, se aprecia el beneficio, aunque no se haya materializado la venta ni se haya producido ningún ingreso económico.

Sin embargo, en el caso enjuiciado esa propiedad se vendió, por lo que la mejora se podía cuantificar de modo preciso, descontando del precio de venta el importe global que la finca costó al acusado, incluyendo los gastos de adquisición (impuestos, notaría, inscripción registral, etc.). La ventaja estaba constituida exclusivamente por el aumento del valor del terreno debido a la recalificación conseguida mediante el soborno. Por lo tanto, no se podía decomisar una suma superior, porque supondría quitar algo que no era un beneficio del delito.

En consecuencia, el principio bruto entraría en juego una vez concretada la ganancia, impidiendo deducir los gastos que supuso la ejecución de la infracción. No se podría descontar, por ejemplo, la comisión ilegal abonada al funcionario, ni los costes que conllevaron los trámites necesarios para la recalificación.

El precio final de venta no era, como pretendía el fiscal, la ventaja del delito, puesto que el terreno ya era propiedad del 
condenado cuando cometió el cohecho, aunque lo había adquirido por un importe muy inferior al conseguido con su venta, gracias a su nueva consideración de urbanizable. El mayor valor alcanzado por la recalificación ilícita integraba la rentabilidad del delito y era, por tanto, el objeto decomisable (etwas).

En realidad, el tratamiento del comiso en estas conductas es sustancialmente distinto al que se ha aplicado hasta ahora en nuestro ordenamiento. En la práctica judicial únicamente se decomisan las ganancias efectivamente obtenidas y no los beneficios estimados o esperados, aunque al igual que en Alemania se parte del denominado beneficio bruto, sin restar $\operatorname{costes}^{48}$. En concreto, en el cohecho se confiscan las comisiones o los bienes ilícitamente recibidos. En cambio, en un supuesto similar al planteado en la sentencia alemana no se le requeriría a quien paga el soborno ni el incremento del valor del bien, ni el precio superior obtenido por la venta.

Por ejemplo, en la STS 684/2013, de 3 de septiembre, se confirmó el comiso de las comisiones cobradas por un alcalde y un concejal de obras, condenados por cohecho, de los adjudicatarios de las mismas. Sin embargo, no se requisó a estos beneficiarios la ventaja que les supuso la adjudicación ilícita, ni los ingresos que en el momento del juicio habían tenido, ni los que pudieran preverse para el futuro.

Ahora bien, la LO 1/2015, de 30 de marzo, suprimió el artículo $431 \mathrm{CP}$, donde se disponía que en los delitos de cohecho y tráfico de influencias se decomisarían las dádivas, presentes o regalos. A partir de la reforma esos delitos se someten a las normas comunes de los artículos 127 a $128 \mathrm{CP}$. Esto supone que el particular que hubiera pagado un soborno y obtenido la consiguiente ventaja patrimonial podría verla decomisada. De todas

48 Puede verse una síntesis de las posturas doctrinales al respecto en, VIZUETA FERNÁNDEZ, J.: "El comiso de las ganancias provenientes del delito y el de otros bienes equivalentes a éstas", en Revista Penal, n 19, 2007, p. 171. 
formas, a mi juicio eso no significa que haya que calcular los beneficios futuros, sino que parece más acorde con la seguridad jurídica privar sólo de lo efectivamente obtenido, partiendo como se viene haciendo del beneficio bruto ${ }^{49}$.

\subsection{Comiso en interés de tercero}

El § 73 apartado 3 StGB dispone que, si el autor o el partícipe ha actuado para otro y ha conseguido algo para él, entonces se expide la orden de comiso contra él de acuerdo con el inciso primero. A continuación, el apartado 4 prevé que el comiso del objeto también procede cuando pertenece a un tercero que lo recibió con conocimiento de las circunstancias del hecho ilícito. La primera disposición no se recoge expresamente en nuestro Código, pero como se desprende de la jurisprudencia del Tribunal Supremo alemán recoge algunos supuestos regulados en el artículo 127 quáter.

\section{de $2013^{50}$}

\section{a) Sentencia del Tribunal Supremo de 3 de diciembre}

RESUMEN: Se estudian los requisitos del comiso de bienes de un tercero, conforme al \$ $73 \mathrm{StGB}$, que en este caso se habia acordado por cometer delito de blanqueo de dinero, modalidad imprudente, del § 261 apartado 5 StGB.

Puntos principales de la sentencia:

1. Conforme al $\$ 73$ apartado 1 StGB, la ganancia obtenida por el autor o el partícipe de un delito se somete al comiso. Como delito, se tiene en cuenta también un delito en grado de tentativa (compárese BGH wistra 2010, 477).

2. Actuar para otro en el sentido del \$ 73 apartado 3 StGB no exige una actuación de representación en sentido propio, sino que se actúe en lugar de otro de manera reconocible, externamente, si bien el que actúa debe estar también, en todo caso, conectado con el delito y debe haber actuado, aunque sea de modo fáctico, en interés del tercero.

49 Ampliamente, BLANCO CORDERO, I.: "La aplicación del comiso...", cit., pp. 60 y ss.

50 (BGH 1 StR 53/13), (hrr-strafrecht.de). 
3. En los casos en que el objeto adquirido no provenga del hecho ilícito propiamente, sino que llegue al tercero a través de algún negocio de transacción, se precisa para que pueda ser decomisado, en todo caso, una relación de enriquecimiento entre el hecho ilicito y la entrada de la ventaja en el patrimonio del tercero (BGHSt 45, 235, 244).

4. La relación de enriquecimiento que precisa el $\$ 73$ apartado $3 \mathrm{StGB}$ presupone que las transacciones sospechosas tienen como fin ocultar el delito, o bien alejar del alcance del acreedor el patrimonio, acrecentado por el delito, del autor o de un tercero. Que exista esta relación de enriquecimiento no se opone a que, por lo general, el autor lleve a cabo un intercambio de activos, primero en interés propio y en todo caso, fácticamente, también en interés del tercero (BGHSt en p. 246). Para concretar esta relación de enriquecimiento la jurisprudencia ha establecido varios grupos de supuestos.

5. Una relación de enriquecimiento existe en especial en los casos de representación, en los cuales el representante se enriquece por esta asignación (empresarial). Entre los supuestos de representación se incluye, en particular, la acción del órgano, representante o encargado en el sentido del \$ $14 \mathrm{StGB}$, pero también la acción del miembro de una organización, que actúe en interés de la misma (BGH, p. 245).

6. Una relación de enriquecimiento existe también en casos de intercambio de activos, cuando el autor del delito entregue gratuitamente el producto del delito al tercero, o lo haga llegar a través de un negocio jurídico sospechoso, para así ocultar el delito o alejar el bien del alcance del acreedor. Esto rige también cuando el producto del delito se mezcle, antes de la trasmisión al tercero, con el patrimonio legal del transmitente o cuando lo trasmitido al tercero supone sólo el ahorro de algún coste (BGH, sentencia de 23 de octubre de 2013 -5 StR 505/12).

7. En este sentido, hay que distinguir el caso de "buen cumplimiento" (Erfüllungsfall). De esta forma se denomina el supuesto en que el autor o partícipe trasmite el producto del delito a un tercero de buena fe, estando ante el cumplimiento de una obligación que no es sospechosa, cuyo nacimiento y contenido no guarda relación alguna con el hecho delictivo. No se puede mantener que aqui el autor del delito actúe-como mínimo de modo fáctico- en interés del tercero. El criterio de 
no existir interés fáctico no impide, en todo caso, que quede abierta la esfera de aplicación del $\$ 73$ apartado $3 \mathrm{StGB}(B G H$ antes citada, p. 247).

8. Para saber si estamos ante un caso de "buen cumplimiento" que implica a terceros de buena fe, en supuestos de negocios de trasmisión interpuestos, tiene un valor decisivo la inmediación. De haber obtenido el tercero el botín del delito o algún beneficio derivado del mismo en virtud de un negocio jurídico remunerado acordado con el autor o el participe del delito, este no es sospechoso ni por sí mismo ni en conexión con el hecho antijurídico, de modo que no se entenderá que el tercero haya obtenido un beneficio a través del delito. Esta restricción se desprende de la jurisprudencia de la sala civil del Tribunal Supremo, derivada de la aplicación paralela de las disposiciones que regulan el enriquecimiento en el Código civil ( $\$ \$ 812$ BGB ss), que el legislador tuvo en cuenta al redactar el $\S 73$ apartado $3 \mathrm{StGB}$...

9. Por tanto, según la jurisprudencia del Tribunal Supremo, es síntoma de supuesto de "buen cumplimiento" el hecho de que el tercero que haya recibido el beneficio del delito, tenga buena fe... Según la jurisprudencia imperante, el comiso de bienes de un tercero tiene su frontera en los casos en que haya tenido lugar algún negocio jurídico con un tercero de buena fe (BGHSt antes citada, 240, 247). El requisito de la buena fe se debe exigir, sin embargo, sólo respecto del punto temporal en que se acuerda el negocio obligacional. De esta manera, se presenta básicamente un caso de "buen cumplimiento" cuando el cumplimiento de una obligación que no puede calificarse de sospechosa se lleva a cabo con el producto de un delito y el receptor contó al menos con parte del mismo.

10. El hecho de que no se colmen los presupuestos del $\S 73$ apartado $3 \mathrm{StGB}$ no impide que se pueda emitir una orden de comiso contra alguien, al amparo del $\S 73$ apartado 1 StGB, cuando haya sido considerado culpable de blanqueo de capitales, al menos en su modalidad imprudente (\$261 apartado $5 \mathrm{St} G B)$.

\section{ANTECEDENTES}

1. El Tribunal Supremo estima el recurso del afectado por el comiso, F., de modo que anula parcialmente la sentencia del 
tribunal regional de 22 de agosto de 2012, por estimar que no era necesario acordar el comiso.

2. Los motivos de apelación esgrimidos por la fiscalia son rechazados.

\section{FUNDAMENTOS JURÍDICOS}

El tribunal regional impuso al afectado por el comiso, F., una cantidad de dos millones de euros...

La defensa del afectado $F$. recurre en apelación, por una doble infracción, de derecho formal y material, al no colmarse los requisitos del $\$ 73$ a ni 73 apartado 3 StGB. Alega básicamente que las prestaciones patrimoniales recibidas no son beneficios (gratuitos) derivados del delito cometido por Fa., sino prestaciones que derivan de un negocio remunerado.

La fiscalía reclama en apelación, en el sentido de que el comiso impuesto a $F$ no debe ser por cantidad de dos millones, sino de cinco millones doscientos mil euros.

El motivo alegado por la defensa de F. se estima, y ello conduce a la anulación de la orden de comiso.

La apelación de la fiscalia no tiene éxito.

\section{Desarrollo del proceso}

$1^{\circ}$. El tribunal regional de Hamburgo condenó..., al ex presidente del consejo de administración de la empresa suiza D.AG., el acusado Fa., por delito de estafa en grado de tentativa, en concurso ideal con falsedad, a una pena privativa de libertad de cuatro años. Además, otros cuatro acusados, que estaban empleados en esta empresa o en otras dependientes de ella, fueron condenados como cómplices de estos delitos o por defraudación de impuestos.

Según la declaración de hechos probados de la sentencia recurrida, Fa., en su condición de presidente del consejo de administración de la empresa suiza D.AG., vendió una participación de más del 75\% de esa sociedad, en diciembre de 2000, a la entidad inglesa $E$, dedicándose ambas a la tecnología de la información. El precio total de compra de la empresa ascendió a 762 millones de euros.

De acuerdo con los hechos probados, los acusados antes de la transacción manipularon deliberadamente facturas, cifras de ventas y documentos con beneficios de la empresa vendida, $A G$, que entregaron a los futuros compradores, para provo- 
car engaño sobre la situación económica real de la empresa suiza $A G$.

III. Recurso del afectado por el comiso F

El motivo de fondo que se esgrime en el recurso interpuesto por la representación de F., afectado por el comiso de una elevada cantidad, se admite, lo que conduce a la anulación de la orden de comiso que se le impuso...

En este apartado se recuerda la doctrina consolidada del Tribunal Supremo respecto de los supuestos en que existe "buen cumplimiento", antes indicada, y se aplica al caso por la sala penal del Tribunal Supremo, concluyendo que F. se benefició del producto del delito, al recibir varios pagos de una persona condenada como estafadora, pero que fue un tercero de buena fe, siendo inapropiada la orden de comiso, que es anulada, por no colmarse los presupuestos del $\$ 73$ StGB, ni el apartado $1^{\circ}$ ni tampoco su apartado $3^{\circ}$. No se aprecia por la sala penal del Tribunal Supremo que exista conexión de enriquecimiento entre los pagos recibidos por F. y el delito previo cometido por el pagador.

\section{b) Exclusión de terceros de buena fe}

El $\S 73$ apartado $3 \mathrm{StGB}$ se refiere a supuestos en los que el autor o partícipe actúa en interés de un tercero, aunque sea de modo fáctico. Cuando el bien del delito no se le entrega directamente sino a través de un negocio jurídico, el Tribunal Supremo requiere para poder practicar el comiso que se produzca un enriquecimiento, de modo que la ventaja ilícita se incorpore al patrimonio del tercero. Este presupuesto se da, por ejemplo, en caso de actuación del representante de una sociedad que mediante la transmisión de elementos ilícitos a la entidad obtiene un beneficio propio. También cuando se realiza una transacción fraudulenta, dirigida a ocultar el delito o a sustraer el patrimonio a la reclamación de los acreedores, y esa operación beneficia al tercero. En este sentido, se presume que existe ese enriquecimiento cuando el autor del delito transfiere el bien al tercero gratuitamente o a través de un negocio jurídico sospechoso. En cambio, falta ese presupuesto en los casos de "buen cumplimiento", es 
decir, si el tercero obtiene de buena fe el bien, desconociendo su origen ilegal. Se entiende que se da este supuesto, excluyendo el comiso, cuando lo recibe a cambio de un precio.

Este comiso particular presenta ciertas similitudes con el regulado en el artículo 127 quáter $\mathrm{CP}$. Ahora bien, el Tribunal Supremo alemán parte de que no se debe practicar cuando es un tercero de buena fe, y presume esta condición si adquiere el elemento delictivo mediante un negocio oneroso. Por el contrario, el precepto español faculta a los jueces y tribunales para acordar el decomiso cuando lo hubiera adquirido con conocimiento de que procede de una actividad ilícita o cuando una persona diligente habría tenido motivos para sospechar, en las circunstancias del caso, de su origen ilícito. Y a estos efectos se dispone que se presumirá, salvo prueba en contrario, que el tercero ha conocido o ha tenido motivos para sospechar que se trataba de bienes procedentes de una actividad ilícita, cuando le hubieran sido transferidos a título gratuito o por un precio inferior al real de mercado.

Por lo tanto, en el sistema alemán esta norma se concibe como una vía para recuperar lo traspasado maliciosamente a un tercero, pero se presupone su buena fe si pagó una contraprestación. Sin embargo, en el ordenamiento español se presume la mala fe siempre que adquirió el objeto por un precio inferior al de mercado, sin requerir siquiera una rebaja sustancial. Además, si ha dispuesto de él, incluso donándolo, se le puede imponer una suma económica por su valor. Como después expondré, así configurada esta figura reviste todas las características de una sanción.

\section{Comiso ampliado}

El $\S 73$ d StGB:

1. Si se comete un acto ilícito, previsto en una ley que remita a esta disposición, el tribunal ordenará el decomiso de objetos del autor o partícipe, en caso de que las circunstancias 
justifiquen presumir que estos objetos fueron adquiridos como resultado de actos ilícitos o con el propósito de cometerlos. Esta frase rige, aunque el autor o el partícipe, alegue que no posee o tiene derecho al objeto meramente por haberlo adquirido como resultado de un acto ilícito o con el propósito de cometerlo. El \$ 73 inciso $2^{\circ}$ rige en lo pertinente.

2. De haberse vuelto total o parcialmente imposible el comiso de un determinado objeto tras el hecho, son de aplicación los $\S 73$ a y 73 b.

3. Si después de emitir la orden de comiso, de conformidad con el apartado 1, debe decidirse de nuevo sobre el comiso de objetos del autor o partícipe, a causa de otro hecho antijurídico que el autor o el partícipe haya cometido antes de esa orden, el tribunal tendrá entonces que tener en cuenta la orden ya dictada.

\section{El $\$ 73$ c rige en lo correspondiente.}

En un principio esta norma recibió críticas, tanto por parte de la doctrina como de algunos tribunales ${ }^{51}$, al considerar que vulneraba la presunción de inocencia y el derecho a la propiedad privada garantizados en la Ley Fundamental ${ }^{52}$. En este sentido se pronunciaba Eser al comentar la "Ley para combatir el tráfico ilegal de drogas y otras manifestaciones de la delincuencia organizada" de 15 de julio de 1992 (OrgKG), que preveía el decomiso ampliado cuando las circunstancias "justifiquen la presunción de que estos objetos fueron adquiridos para hechos antijurídicos o que provienen de ellos". A su juicio, esta disposición infringía los principios de presunción de inocencia y culpabilidad $^{53}$. Sin embargo, tanto el Tribunal Supremo, como el Tribunal Constitucional avalaron esta norma.

51 (BT-DRs 12/989, 23). SCHÖNKE, A./SCHRÖDER, H.: Strafgesetzbuch Kommentar, cit., p. 575.

52 KÜHL, K.: Strafgesetzbuch Kommentar, cit., p. 527.

53 ESER, A.: "Neue Wege der Gewinnabschópfung im Kampf gegen die organisierte Kriminalitat?", en DENCKER, F. (Coord.): Beiträge zur Rechtswissenschaft. Festschrift Walter Stree und Johannes Wessels zum 70. Geburtstag, C.F. Müller Juristischer Verlag, Heidelberg, 1993, pp. 844 y ss. 


\subsection{Postura del Tribunal Supremo}

\section{a) Sentencia de 1 de marzo de $1995^{54}$}

\section{FUNDAMENTOS}

1. El acusado, de 33 años al suceder el delito, vivía con su novia sin ingresos fijos en una vivienda en F. Había estudiado hasta 1992 y ahora quería seguir estudiando. En ningún momento acreditó ingresos que le permitieran ahorrar una suma de dinero considerable. El 9 de marzo de 1994 fue registrada su casa por ser sospechoso de haber trasportado, junto a su novia, una gran cantidad de hachis a Dinamarca. Alli se encontraron $2,8 \mathrm{~kg}$ de hachis de buena calidad, que el acusado quería vender, y en un maletín negro había una gran suma de dinero, dividido en bolsas -un total de 73.169 marcos alemanes-.

El tribunal regional tuvo la convicción de que dichas cuantías procedian de la venta de drogas. Lo condenó por tráfico de estupefacientes, en cantidad no reducida, a una pena privativa de libertad de tres años y cuatro meses, y acordó el comiso, conforme al $\$ 73$ d StGB, de la suma encontrada de 73.160 marcos.

2. El recurso de los acusados se basa en infracción de derecho material y formal. Está infundado. La sentencia impugnada está libre de toda tacha jurídica, incluyendo el punto del comiso ampliado, pero no se ha valorado expresamente esta circunstancia en la determinación de la pena, lo que es objeto de recurso.

3. El tribunal regional aplica correctamente el contenido del $\S 73$ d StGB. Está convencido de que el dinero tiene origen delictivo. Deducir de ello, como hace el recurrente, que el tenor literal de la ley y la voluntad del legislador imponen al juez rebajar en grado la pena, partiendo de la señalada en abstracto, no es admisible. El hecho de que ese comiso no tiene efecto atenuador en los delitos relacionados con una obtención de dinero está reconocido desde hace tanto tiempo que no merece mayor discusión.

4. También el fallo se confirma.

5. Que el tribunal regional no haya valorado a su favor, al determinar la pena, el comiso de ese dinero, no es ningún error

54 (www.jurion.de/urteile/bgh/1995-03-01/2-str-331_94). 
jurídico. La pérdida de los efectos relacionados con el delito no puede ser una atenuante penal. No cabe alegar que el $\$ 46.1^{\circ}$ frase 2 StGB imponga tener en cuenta, al determinar la pena, los efectos que se espera que ésta tenga en la vida futura del condenado en la sociedad...

6. El comiso sirve en todo caso para privar al condenado de la ganancia ilícita y con ello compensar la trasferencia ilegal de la riqueza. Este fin determina su naturaleza jurídica. De ahi se deduce que no hay razón para que influya en la determinación de la pena...

7. El fin y la naturaleza jurídica del comiso tampoco ha experimentado variación tras la Ley de 28 de febrero de 1992. Esta ley ha introducido el "principio bruto" (Bruttoprinzip), según el cual debe declararse la pérdida no sólo de lo que supuso una ganancia, sino de todo aquello que el autor adquirió "como resultado de actos ilícitos o con el propósito de cometerlos". A ello se vincula el instituto del comiso ampliado surgido en esa ley.

\section{b) Comentario}

En estos primeros pronunciamientos del Tribunal Supremo sobre la nueva figura del comiso ampliado, confirmaba que la sustitución de la expresión Vermogensvörteil ("ganancia patrimonial") por etwas ("algo") en el § $73 \mathrm{StGB}$, implicaba el abandono del "principio neto" (Nettoprinzip) y la adopción del "principio bruto" (Bruttoprinzip). Esto suponía que no se decomisaría simplemente la ganancia efectiva, sino todo lo adquirido por el delito o con el propósito de cometerlo, sin entrar a valorar por tanto el desembolso que el responsable hubiera tenido que realizar para lograrlo.

Pero a su vez esta nueva perspectiva servía de fundamento para la institución del comiso ampliado, en tanto se perseguía privar al condenado de todos los bienes procedentes de un acto ilícito, o destinados a realizarlo.

En el supuesto juzgado el hecho de no acreditar ingresos, unido a la posesión ilegal de hachís, fueron considerados indicios suficientes para presumir que el dinero intervenido procedía del tráfico de drogas. 
Por otra parte, la naturaleza del comiso como medida dirigida a evitar el enriquecimiento ilícito, determinaba que su imposición no diera lugar a una reducción de la condena. El § $46 \mathrm{StGB}$ al regular el fundamento de la determinación de la pena establece que, además de la culpabilidad del sujeto se tendrán en cuenta otras circunstancias, entre ellas, los efectos que se espera que la pena impuesta tenga en la vida futura del condenado, así como sus circunstancias personales y económicas. Pero esta disposición no afecta al comiso puesto que carece de naturaleza penal.

\subsection{Interpretación del Tribunal Constitucional}

\section{a) Auto de 14 de enero de $2004^{55}$}

Se rechaza el recurso de inconstitucionalidad.

$1^{\circ}$. El comiso ampliado ( $\left.\$ 73 \mathrm{~d} \mathrm{St} G \mathrm{~GB}\right)$ no persigue fines de tipo represivo, sino de orden preventivo, y por eso no es una medida asimilada a las penales, que se basan en el principio de culpabilidad.

$2^{\circ}$. El $\$ 73$ d StGB no infringe el principio de presunción de inocencia.

$3^{\circ}$. La presunción del origen delictivo de un bien, en el sentido del § 73 d frase 1 StGB está justificada cuando el juez se convence de ello tras practicar los medios de prueba pertinentes.

\section{FUNDAMENTOS}

A. Este recurso de amparo constitucional requiere el estudio de la compatibilidad del $\$ 73$ d StGB (comiso ampliado) con la Ley Fundamental. Al mismo tiempo se dirige contra la aplicación de esta norma del modo en que se interpreta por el Tribunal Supremo.

I. El $11 n^{\circ} 7$ de la Ley para combatir el tráfico ilícito de drogas y otras manifestaciones de la delincuencia organizada (OrgKG) de 15 de julio de 1992 introdujo el $\$ 73$ d, relativo al comiso ampliado, en la parte general del Código penal...

II. 1. El recurrente fue condenado el 11 de mayo de 1994 por el tribunal regional como autor de dos delitos de tráfico ilícito de drogas, en cantidad no pequeña, a pena total de siete

55 (BVerfGE 110), (https://openjur.de/u/197013.html). 
años de prisión. Se acreditó que él (en ambos casos con otro autor) acordó por teléfono el 15 de octubre de 1992 la compra de tres kilogramos de heroina, y el 1 de agosto de 1993 adquirió un kilogramo de heroína.

Además, el tribunal regional le impuso una medida, conforme al $\$ 69$ y al $\S 69$ a StGB, por la que le fue incautado el dinero que tenía en su cuenta corriente, 42.520,18 marcos alemanes. El tribunal concluyó que este dinero procedía de transacciones de droga. Razonó en la sentencia que el recurrente ganaba 850 marcos mensuales y no podia prescindir de los gastos generales de la vida, como comida y bebida, coste de funcionamiento de su coche y alquiler mensual, de 600 marcos. Se acreditó que las dos personas juzgadas se habian dedicado profesionalmente a la venta de estupefacientes - a pesar de que en los delitos probados no se había logrado ningún beneficio (en un caso, porque el negocio no se materializó, en el otro, porque la droga adquirida fue confiscada)-pero el Tribunal asumió que habian traficado con drogas, careciendo de indicios de cualquier otro comportamiento criminal del recurrente. Por todo ello, los miembros del tribunal estaban convencidos de que el dinero sólo podía proceder de la venta de droga.

2. El recurso interpuesto por el recurrente contra la sentencia por infracción de fondo y procesal fue rechazado por la sala penal del Tribunal Supremo...

La medida de comiso ampliado ejecutada contra el recurrente se estimó fundada en una razón jurídica válida. La sala admitió que la doctrina jurídica había planteado dudas sobre la compatibilidad del $\$ 73$ d StGB con la presunción de inocencia y el derecho a la propiedad privada, y sólo podría evitarse esa cuestión a través de una interpretación conforme a la Ley Fundamental:

El comiso ampliado recogido en el $\$ 73$ d StGB sólo exige que el juez presuma con "muy alta probabilidad" que "estos objetos fueron adquiridos como resultado de actos ilícitos o con el propósito de cometerlos". Esto elimina toda sospecha de infracción constitucional en el comiso ampliado, pues descansa en una acusación de delito. Por eso, existe un elemento normativo, "que las circunstancias justifiquen presumir que estos objetos fueron adquiridos como resultado de actos ilícitos o con el propósito de cometerlos", lo que permite realizar una interpretación conforme a la Ley Fundamental... 
La disposición del comiso ampliado sólo se toma en consideración si el juez sentenciador tiene la evidencia y la plena convicción de que habia adquirido los objetos como consecuencia de actos ilegales. Sin embargo, no es necesario un detalle exhaustivo de las investigaciones realizadas. Para llegar a esa convicción no deben exigirse explicaciones minuciosas. En este caso particular, el tribunal regional sentenciador no omite su razonamiento, que le lleva a esa creencia, a pesar de que no se acreditó ganancia en los delitos objeto de condena. Estos requisitos se cumplen con las explicaciones dadas en la sentencia sobre las circunstancias personales y económicas del recurrente.

III. Contra la sentencia del tribunal regional y la de la sala penal del Tribunal Supremo que la confirmó, uno de los condenados ha interpuesto recurso de amparo, alegando la infracción de varios derechos constitucionales $-\$ \S 14,20.3^{\circ}$ y $103.2^{\circ}$ de la Ley Fundamental-partiendo de que la medida de comiso ampliado que se le ha aplicado, prevista en el $\$ 73 d$ StGB, tiene carácter de pena, según la concepción del recurrente...

$B$. Una de las infracciones alegadas es admisible sólo parcialmente.

Se aduce vulneración del principio de irretroactividad de disposiciones sancionadoras del $\$ 103.2^{\circ}$ de la Ley Fundamental, puesto que la norma del comiso ampliado se contiene en el $\S 73 d$ StGB y se ha aplicado a un condenado en un momento en que no había entrado todavía en vigor... El condenado se ha descuidado al no plantear en el recurso, en segunda instancia, esa alegación, por infracción del principio de irretroactividad. Ello impide al Tribunal constitucional pronunciarse sobre el tema.

C. El resto de alegaciones de inconstitucionalidad se admiten, pero una vez estudiadas se estiman infundadas, por los siguientes motivos.

I. El $\S 73$ d StGB es conciliable con la Ley fundamental de acuerdo con la interpretación del Tribunal Supremo.

$1^{\circ}$. El $\S 73$ d StGB no infringe el principio de culpabilidad.

a) El principio "no hay pena sin culpabilidad" (nulla poena sine culpa) está anclado en la garantía de la dignidad y de la autodeterminación del ser humano ( $\$ \$ 1.1$ y 2.1 de la Ley Fundamental) así como en el principio del Estado de Derecho. 
Este principio exige que las penas o las sanciones asimiladas a ellas sean proporcionadas a la gravedad del hecho y a la culpabilidad del autor...

Pena es toda imposición de un perjuicio jurídico a causa de un hecho antijurídico cometido con culpabilidad. La pena es una medida, de carácter jurídico penal, dirigida, junto a su labor de resocialización, a formular un reproche proporcionado a cierta conducta prohibida. Todas las penas deben ser conformes al principio de culpabilidad. Las medidas de tipo penal se asocian a una pérdida de libertad o de activos patrimoniales.

b) La institución jurídica del comiso ampliado no entra en conflicto con el principio de culpabilidad, porque no tiene carácter de pena o sanción asimilada. Una interpretación del $\S$ 73 d StGB sistemática, acorde al tenor literal y a la tradición legislativa, supone que la desposesión amparada en el precepto no se dirige a captar la ventaja patrimonial obtenida delictivamente ni a reprochar al afectado la realización de un hecho ilícito como origen de la misma, ni por tanto pretende causarle un mal retributivo. Más bien el $\$ 73$ d persigue unos fines de estabilización de la norma y de ordenación del patrimonio. Esto supone que el comiso ampliado no altera la vigencia del principio bruto.

aa) El Código penal no caracteriza al comiso ni al comiso ampliado como penas, sino como "medidas", entre las cuales, conforme al § 11 párrafo $1 n^{\circ} 8 \mathrm{St} G B$ y al \$ $61 \mathrm{St} G B$, se encuentran también las medidas de corrección y seguridad.

$2^{\circ}$. El $\S 73$ d StGB es conciliable con el principio de presunción de inocencia.

a) La presunción de inocencia es una regla básica del Estado de Derecho. Debe respetarse en el proceso penal y exige que un reproche se base en la constatación de ciertos hechos.

b) El instituto jurídico del comiso ampliado no infringe este principio. El $\& 73$ d StGB permite la privación de bienes patrimoniales de una persona, cuando se presume que proceden de hechos ilícitos, pero no necesariamente de hechos delictivos cometidos con culpabilidad. La regulación del comiso ampliado no presupone la existencia de culpabilidad. Por tanto, la ley que la regula no la vincula a una culpa decretada judicialmente.

$3^{\circ}$. El contenido del $\S 73$ d StGB no infringe la garantía constitucional del $\S 14.1^{\circ}$ de la Ley Fundamental, conforme a la interpretación de la sala penal del Tribunal Supremo. 


\section{b) Recapitulación}

El Tribunal Constitucional confirma la adecuación del comiso ampliado a la Ley fundamental. El motivo central es que no tiene carácter de pena o sanción asimilada a ella. No se dirige a captar la ventaja patrimonial obtenida por el delito como reproche por la realización del hecho ilícito que la originó. De manera que no tiene carácter retributivo, sino que sus fines son más bien la estabilización de la norma y la ordenación del patrimonio.

Desde este punto de vista, el comiso ampliado no infringe los principios de culpabilidad y de presunción de inocencia, asociados a las penas.

Por otra parte, la ley exige que haya indicios objetivos de la procedencia ilícita de los bienes ("que las circunstancias justifiquen presumir que estos objetos fueron adquiridos como resultado de actos ilícitos o con el propósito de cometerlos"), por lo que el tribunal no puede acordarlo de forma arbitraria.

Curiosamente, se rechaza por motivos formales un fundamento tan trascendente como la irretroactividad de las normas penales, puesto que el recurrente alegaba que el $\S 73 \mathrm{~d}$ StGB no había entrado en vigor cuando se le quitaron los bienes procedentes presumiblemente del tráfico de drogas.

Pues bien, como decía, algunos de los argumentos aportados en esta resolución han sido reproducidos en la Exposición de Motivos de la Ley Orgánica 1/2015, de 30 de marzo. No obstante, nuestro legislador atribuye al decomiso tan sólo un propósito de ordenación del patrimonio y omite, en cambio, el de estabilización de la norma al que alude el Tribunal Constitucional alemán, tal vez por las connotaciones preventivas que conlleva y que se suelen asociar a las respuestas penales. Por otra parte, no dice que una parte del contenido del decomiso español (de los productos e instrumentos del delito) en Alemania se regula mediante otra institución diferente, la confiscación, que no se considera una medida civil sino una pena accesoria. 


\section{Confiscación}

\subsection{Regulación}

\section{$\S 74$ StGB. Presupuestos de la confiscación}

1. De cometerse un delito doloso, el tribunal puede confiscar los objetos que se obtuvieron mediante el hecho punible o que se hayan utilizado para su comisión o preparación, o se hayan destinado a tal fin.

2. La confiscación sólo está permitida cuando:

1) los objetos pertenezcan en el momento de decidir al autor o al partícipe $o$,

2) los objetos pongan en peligro a la comunidad según su clase y circunstancias, o exista el peligro de que se utilicen para cometer hechos antijurídicos.

3. Bajo los presupuestos del párrafo 2 del número 2 también cabe la confiscación de objetos que hayan sido utilizados cuando el autor actuó sin culpabilidad.

4. Si se acuerda la confiscación conforme a un precepto distinto al apartado $1^{\circ}$ anterior, rigen en lo correspondiente los incisos segundo y tercero. confiscación

$\S 74$ a. Ampliación de los presupuestos que permiten la

Si la ley remite a este precepto, entonces se pueden confiscar los objetos también cuando no pertenezcan al autor o partícipe, como exige el $\$ 74$ apartado $2^{\circ} n^{\circ} 1$, siempre que el propietario del objeto, en el momento de la decisión de confiscación:

1. Haya contribuido al menos imprudentemente a que la cosa o el derecho hayan sido el medio de cometer o preparar el acto ilícito, $o$

2. Haya adquirido los objetos de forma reprobable, con conocimiento de las circunstancias del acto ilícito.

\section{$\S 74$ b. Principio de proporcionalidad}

1. De no ser obligada la confiscación, no debería acordarse en los supuestos del $\$ 74$ apartado $2 n^{\circ} 1$ y del $\$ 74$ a, o en los casos del apartado 3 del $\$ 74$ a, cuando en atención al hecho cometido y al reproche que merezca el autor o partícipe, la confiscación sea desproporcionada. 
2. En los casos especificados en los $\$ \$ 74$ y 74 a, el tribunal no acordará la confiscación cuando la recuperación se pueda conseguir con medidas menos gravosas y adoptará una medida menos restrictiva. En particular puede imponer ciertas obligaciones, 1) inutilizar los objetos; 2) eliminar de los objetos ciertos dispositivos o características o modificarlos de otro modo; 3) disponer de los objetos de cierta manera.

Si se respetan esas obligaciones el tribunal anulará la confiscación, de lo contrario, el tribunal la ordenará.

3. De no ser obligada la confiscación, puede limitarse a parte de los objetos.

\section{$\S 74$ c. Confiscación del valor sustitutivo}

1. Cuando el autor o participe haya explotado el objeto, que le pertenecía en el momento del hecho, antes de que se decida su confiscación, enajenándolo o consumiéndolo, el tribunal puede ordenar la confiscación de una suma de dinero contra el autor o el partícipe hasta la cantidad del valor del objeto.

2. Tal orden puede tomarse también cuando el objeto haya sido sometido por el autor o participe, antes de que se acuerde su confiscación, a un derecho a favor de un tercero cuya extinción no pueda ordenarse sin una reparación o en casos en que no quepa la confiscación (\$\$ 74 e párrafo 2 y 74 f). Si el tribunal impone la orden junto con la confiscación, entonces calculará el precio del valor de la afectación del objeto.

3. El valor del objeto y de su afectación pueden ser tasados.

4. Para la concesión de facilidades de pago rige el $\$ 42$ en lo pertinente.

Por lo tanto, la confiscación recae sobre los objetos producto del delito y sobre los empleados para prepararlo o ejecutarlo, o que estuvieran destinados a cometerlo. Esta última cláusula, que no se contempla en el Derecho español, permite requisarlos aunque no se hayan utilizado, si por ejemplo se tuviesen disponibles para su eventual uso ${ }^{56}$. No obstante, se excluyen 1 os objetos que forman parte del tipo, como el vehículo que se

56 AGUADO CORREA, T.: "La regulación del comiso en el Proyecto de modificación del Código penal", en Revista Electrónica de Ciencia Penal y Criminologia, 05-04, 2003, p. 4, (http://criminet.ugr.es/recpc). 
conduce sin permiso ${ }^{57}$, lo que no sucede en nuestro ordenamiento (art. 385 bis CP).

Pues bien, a diferencia del comiso, se considera que la confiscación es una pena accesoria, salvo cuando se acuerda por razones de seguridad ${ }^{58}$, o recae en publicaciones ${ }^{59}$. Eso hace que se prevea con carácter facultativo y no obligatorio como en el artículo $127 \mathrm{CP}$ y que su aplicación se regule de forma restrictiva, con sujeción en todo caso al principio de proporcionalidad.

Por lo tanto, la privación de los productos del delito y de los objetos empleados en su preparación o ejecución tiene carácter de pena cuando pertenecen al autor o el partícipe ( $\S$ $\left.74.2, \mathrm{n}^{\mathrm{o}} 1 \mathrm{StGB}\right)$. En estos casos se permite imponer una cuantía económica por el valor del bien si lo ha enajenado o consumido, o si ha atribuido un derecho a un tercero de manera que para recuperarlo sea necesaria la reparación o que haga inviable la confiscación (§ 74 c StGB). Asimismo, se establece la posibilidad de confiscar objetos propiedad de un tercero, si ha contribuido al menos por imprudencia a su utilización en el hecho delictivo, o si los ha adquirido tras su comisión de un modo reprochable, con conocimiento de las circunstancias del acto ilícito ( 774 a StGB). En este punto se diferencia del artículo 127 quáter $\mathrm{CP}$, que prevé el decomiso de los efectos, ganancias o instrumentos adquiridos por un tercero, no sólo cuando conociera su procedencia ilícita, sino también si una persona diligente hubiera tenido motivos para sospechar del origen ilícito de los bienes o efectos, o de que dificultaba el decomiso de los instrumentos. Además, en estos casos se puede imponer al tercero una suma equivalente, mientras que esta posibilidad en Alemania se reduce a los responsa-

57 JESCHECK, H.H.: Tratado de Derecho penal. Parte general, Comares, Granada, 2002, p. 858.

58 Proponía la incorporación en nuestro Derecho de medidas menos gravosas que el decomiso, como las previstas en el $\S 74 \mathrm{~b}, \mathrm{n}^{\circ} 2$, MANZANARES SAMANIEGO, J.L.: "El Comiso y la Caución en la propuesta de nuevo Anteproyecto de Código penal", en Boletín de Información. Ministerio de Justicia e Interior, $\mathrm{n}^{\circ} 38$ (1342), 1984, p. 7, (http://www.mjusticia.gob.es).

59 Regulado en el $\S 74 \mathrm{~d}$ StGB. 
bles. En cambio, en nuestro Código no se contempla el decomiso de los instrumentos con los que se cometió el delito si eran propiedad de un tercero, facultad que sí recoge el § 74 a StGB, cuando el titular contribuyó a su uso al menos por imprudencia.

\subsection{Interpretación del Tribunal Supremo}

\section{a)Sentencia de 31 de marzo de $2016^{60}$}

\section{ANTECEDENTES}

1. Desestima el recurso del acusado H.H contra la sentencia del tribunal regional de Darmstadt de 18 de febrero de $2015 \ldots$

3. En cuanto al recurso interpuesto por el otro acusado, $M$., el Tribunal Supremo lo estima parcialmente, anulando parte de la sentencia, en el apartado de determinación de la pena y también en la decisión de imponer una confiscación. Los otros motivos del recurso se desestiman.

4. Respecto al alcance de la anulación, el Tribunal Supremo remite la causa a una sala distinta del tribunal regional, para que someta el asunto a nueva vista, emitiendo otra sentencia en la que resolverá también sobre las costas del recurso.

\section{FUNDAMENTOS JURÍDICOS}

El Tribunal regional condenó al acusado M. por tráfico ilegal de estupefacientes en cantidad no pequeña, a pena de prisión de tres años y nueve meses, y al acusado H.H. por complicidad con el anterior, a pena de un año y tres meses de prisión... Además, acordó en la sentencia la confiscación de un terreno del acusado $M$.

I. El recurso del acusado H.H se rechaza totalmente por estar infundado, ya que un examen de la sentencia impide apreciar error de cualquier tipo.

II. El recurso del otro acusado, $M$. merece ser estimado parcialmente:

... 2) Un examen de las razones alegadas en la apelación conduce al tribunal a apreciar que no hubo error de derecho, en cuanto a la culpabilidad del acusado. Sin embargo, existen

60 (BGH 2 StR 243/15), (hrr-strafrecht.de). 
fuertes dudas, de hecho y de derecho, sobre la medida de confiscación del terreno. Ello conduce a la sala a anular la imposición de la pena en ese aspecto.

A. Según los hechos probados de la sentencia, el acusado M. cultivaba una variedad de plantas de cannabis en un terreno... Las plantas fueron descubiertas en mayo de 2014, con un peso total de $15.475 \mathrm{~kg}$ y un contenido de principio activo de al menos un $11,5 \%$.

B. El fundamento para acordar la confiscación del terreno no tiene consistencia:

aa. Un terreno es apto para ser confiscado, como medio o instrumento del delito, en el sentido del \$ 74 apartado 1 StGB. Todo objeto que se ha usado para cometer o preparar el delito (instrumenta sceleris) podría ser confiscado. La confiscación puede decidirse, a discreción del tribunal enjuiciador. Pero entre los fundamentos de la sentencia debe indicarse qué finalidad busca el juez sentenciador al acordar la confiscación, pues puede darse la prevista en el $\$ 74$ apartado $2 n^{\circ} 1$, la del $\S 74$ apartado $2, n^{\circ} 2 \mathrm{StGB}$, o perseguir ambas. Deben también indicarse las razones en que se basa esa medida (según se indica en sentencias del TS de 23 de agosto de 2011 y 4 de enero de 1994). La confiscación prevista en el $\$ 74$ apartado $2^{\circ} n^{\circ} 1$ tiene el carácter de una pena accesoria y rigen por ello las normas de determinación de la pena. Por lo tanto, el razonamiento de la sentencia debe expresar que el tribunal ha reconocido el carácter de pena de la confiscación $y$, en consecuencia, debe resolver si su ejercicio es necesario, como complemento de la pena principal y tras realizar una consideración proporcionada de los fines de la pena (compárese BGHSt 10, 337, 338).

Aun cuando la confiscación puede no ser desproporcionada en el sentido del \$ 74 apartado 1 StGB, se impone una medida menos drástica en el $\$ 74$ apartado 2 StGB cuando el fin de la confiscación pueda alcanzarse también por medio de ella. Este precepto tiene carácter coactivo como expresión del principio de proporcionalidad, y el juez sentenciador debe expresar si no hubo manera de lograr el objetivo buscado a través de medidas más suaves.

bb. Las insuficientes explicaciones recogidas en la sentencia impugnada impiden dar por colmados tales requisitos. No se puede deducir, leyendo la sentencia apelada, cuál es el 
propósito de la confiscación del terreno. No se indica si lo que se pretende es empeorar la situación económica del acusado, o si se estima que la misma finalidad de la pena precisa, en este caso, además de la pena de prisión impuesta, esta medida de confiscación.

cc. Esta sala no puede descartar que la decisión de confiscar el terreno descanse en el error de derecho apuntado por el recurrente.

C. Esta sala acuerda anular la decisión de confiscación y que se emita nueva sentencia por otra sala de ese tribunal regional. La sala no puede, por último, excluir que la nueva sentencia que se dicte imponga una posible confiscación, con la consiguiente pérdida financiera que ello supone, e indica, con vistas a una posible confiscación de carácter asimilable a la pena, que podría reducir la extensión de la pena de prisión impuesta, conforme al principio de adecuación a la culpabilidad.

\section{b) Sentencia de 11 de mayo de $2016^{61}$}

\section{ANTECEDENTES DE HECHO}

En los hechos probados de la sentencia del tribunal regional se da por acreditado que el acusado..., adquirió, en 55 casos, diversos paquetes de cigarrillos -un total de 62.593-en los mercados de Varsovia... Vendió luego esos cigarrillos en la zona de Hamburgo, sin haber pagado impuestos, cobrando al menos 1,5 $€$ y un máximo de $2 €$ por cada cartón de cigarrillos.

En alguna ocasión un Audi Q5 sirvió de vehículo de acompañamiento... A veces lo ocupaba sólo su propietario y en ocasiones también el acusado. Conocía que el camión escoltado poseía cigarrillos, libres de impuestos, cuando superaba la frontera polaco-alemana.

El tribunal regional calculó que en esos 55 trasportes de tacaco se dejó de pagar una cantidad de impuestos de 1.887.689,84 $€$, de los cuales 71.750,20 € correspondian al último viaje. En éste el acusado seguía al camión en un Audi Q5, que fue incautado, y estaba acompañado del propietario del vehículo.

61 (BGH StR 118/16), (http://www.hrr-strafrecht.de/hrr/1/16/1-118-16.php). 


\section{FUNDAMENTOS}

1. La condena por defraudación de impuestos que se impuso al acusado, al no pagar el derivado del tabaco, es correcta, partiendo de los hechos declarados probados...

2. El tribunal regional acuerda el comiso de 93.889,50 $€$, valor de los cigarros, como cantidad compensatoria al amparo del $\$ 73$ apartado 2 frase 2 y $\$ 73$ a StGB. El tribunal regional parte de la concepción de que el acusado obtuvo esos cigarros a través de la comisión del delito de defraudación de impuestos, y no es adecuado. Debía limitar el comiso a la ganancia obtenida por la venta de los cigarrillos sin pagar los tributos. El § 73 apartado $2 \mathrm{StGB}$ permite ampliar el comiso a objetos que el autor o su cómplice hayan adquirido a través de los objetos conseguidos con el delito. Mediante la venta de cigarrillos, sin pagar impuestos, han ganado al menos 1,5 $€$ por cartón. El fisco nada obtuvo con esas ventas. Nada se opone a acudir al § 73 c StGB para imponer el comiso de una cantidad compensatoria, proporcionada a la ganancia obtenida por el acusado. En el delito tributario debemos tener en cuenta la cantidad ahorrada al no pagar el impuesto para colmar el "algo" del § 73 apartado 1 StGB, porque el delincuente ahorró el abono de esos impuestos. La mercancía cuya venta devenga el tributo, aqui impagado, no debe tenerse en cuenta para fundar el comiso del \$73, aunque podría valorarse conforme al $\$$ 375 apartado 2 frase 1 de la Ley Tributaria (Abgabeordnung), que permite su confiscación.

Así, se ha decretado un comiso (Verfall) y lo adecuado era imponer confiscación. Esto es, el § 74 c StGB permite acordar la "confiscación" de una cantidad coincidente con el valor de los cigarrillos. Conforme al \$ 375 apartado 2 frase 1 de la Ley Tributaria cabe imponer una consecuencia accesoria al autor de una infracción tributaria de impago de impuestos, consistente en la confiscación de los objetos que no han tributado.

Si el autor ha dispuesto antes de estar a disposición judicial-como aqui sucede-las mercancías cuya venta producía el devengo del impuesto, no cabe esa confiscación, y el tribunal podrá, conforme al § 74 c StGB, imponerle en sentencia una cantidad compensatoria, que puede llegar hasta la suma en que fueran valorados esos objetos... 
La posibilidad de que, en vez del comiso de una cantidad compensatoria, por el valor de los cigarrillos, como el tribunal hizo, al amparo del § 73 StGB, sea admisible en Derecho otra solución, bien imponer la confiscación de los cigarrillos no vendidos, conforme al § 375 Ley Tributaria, o una "confiscación de una cantidad compensatoria" conforme al § 74 c StGB, obliga a anular la sentencia por afectar a la pena en su conjunto, devolviendo la causa al tribunal. De hecho, la medida de confiscación del § 375 Ley Tributaria es una pena accesoria $y$ debe reflejarse en el apartado de determinación de la pena.

Esta sala penal no puede excluir que el tribunal regional hubiera impuesto una pena de prisión menor si en vez de acordar el comiso del § 73 a StGB optara por la confiscación del § 74 c StGB. No obstante, debe persistir el carácter condenatorio de la sentencia.

3. Se estima el recurso interpuesto por el afectado por la confiscación como propietario del vehículo Audi Q5.

Se da por probado que el Audi Q5 era un vehículo de apoyo, que habia de guiar o proteger al camión que portaba los cigarrillos libres de impuestos, por lo que se equipara a ser el medio de transporte.

La remisión del § 375 apartado 2 frase 2 de la Ley Tributaria al \$ 74 a StGB permite que ciertos objetos puedan ser confiscados si aquel a quien pertenecían en el momento de ocurrir el delito ha contribuido de forma relevante al mismo, aunque sea de modo imprudente. Aqui estriba lo más importante. Se da por probado que el propietario del Audi Q5 conocía el contenido del camión y sabía que iba a cruzar la aduana sin pagar impuestos, ayudando al acusado a que tuviera éxito esa acción. Pero no se fundamenta una medida tan drástica, de modo que no parece que el tribunal haya sido consciente de que priva a un tercero de un vehículo, sin poder leerse en la sentencia una mínima explicación que justifique la privación del mismo en la relevancia de la conducta del propietario en la comisión del delito. La confiscación es una medida que debe tomarse de forma motivada, (Sentencia del TS alemán de 23-08-2011, 4StR 385/11) y el tribunal no explica qué razones ha tenido para adoptarla.

Ante esa carencia de fundamento, la sala penal del Tribunal Supremo no puede examinar si el tribunal ha impuesto 
la medida de confiscación de forma mesurada. En el ejercicio de ese criterio debe atenderse, en especial, a la proporcionalidad del § 74 b StGB. Debe considerarse el valor del objeto incautado, bajo qué circunstancias lo adquiere el titular y su colaboración en el delito tributario, en especial si tuvo alguna responsabilidad, como cómplice o cooperador, en su ejecución. Los fundamentos de la sentencia del tribunal regional no reflejan que se hayan hecho estas consideraciones.

Por ello, la sala penal del Tribunal Supremo acuerda anular la sentencia y devolverla al tribunal regional para que otra sala distinta a la que ya enjuició realice nuevo juicio y resuelva, de modo motivado, sobre si procede la confiscación de una cantidad compensatoria por el valor de los cigarrillos vendidos y si procede la confiscación del Audi Q5 conforme al § 375 apartado 2 frase 1 de la Ley Tributaria en relación con el $\$ 74$ $f S t G B$.

\section{c) Síntesis}

El Tribunal Supremo confirma que la naturaleza de la confiscación es enteramente distinta a la del comiso. Sobre esta figura ha declarado que no tiene finalidad penal, puesto que sirve únicamente para privar al responsable de la ventaja ilícita obtenida por el delito. En consecuencia, la imposición de la pena y del comiso son aspectos diferentes que no deben interferirse entre sí y niega que la cuantía impuesta en este concepto tenga que descontarse de la primera. En Alemania esta precisión es importante porque el $\S 46 \mathrm{StGB}$ dispone que en la determinación de la pena se tendrán en cuenta, entre otros elementos, los efectos previsibles de la misma en la vida futura del condenado y sus circunstancias personales y económicas. Esta naturaleza patrimonial fue confirmada por el Tribunal Constitucional, que avaló el comiso ampliado, afirmando que su fin no es la retribución sino la estabilización de la norma y la ordenación del patrimonio (STC de 14 de enero de 2004).

Respecto a la confiscación, debe diferenciarse la prevista en el $\S 74$ apartado $2^{\circ} \mathrm{n}^{\circ} 1$ (de los objetos que se obtuvieron mediante el hecho punible o se utilizaron para su comisión o 
preparación, cuando pertenezcan en el momento de decidir al autor o al partícipe), de la del $\mathrm{n}^{\mathrm{o}} 2$ (cuando los objetos pongan en peligro a la comunidad, o exista el peligro de que se utilicen para cometer hechos antijurídicos), puesto que ambas tienen naturaleza distinta. Esta última no es una pena, sino que se ordena por motivos de seguridad. En cambio, la del $\mathrm{n}^{\circ} 1$ es una pena accesoria, por lo que se ha de justificar en la sentencia su necesidad como complemento de la pena principal, teniendo en cuenta los fines de las sanciones punitivas. Además, según el $\S$ $74 \mathrm{~b}$ apartado $1 \mathrm{StGB}$ se debe valorar en todo caso si la confiscación es proporcionada, a la vista de la gravedad del hecho y del reproche que merece el sujeto. En este sentido, cuando los objetivos que se persiguen pueden alcanzarse por alguna de las medidas recogidas en el $\S 74$ apartado 2 StGB, debe acudirse a estos medios menos gravosos. Al igual que en el comiso, se excluye directamente la confiscación cuando sea desproporcionada, a diferencia del artículo $128 \mathrm{CP}$ que faculta al órgano judicial para prescindir del decomiso.

En la segunda sentencia el Tribunal Supremo subraya la necesidad de decomisar tan solo la ventaja patrimonial obtenida directamente del delito. De modo que en la resolución recurrida no se debió imponer el precio obtenido por el tabaco vendido sin pagar impuestos, sino únicamente la cuantía defraudada, puesto que el importe ingresado no se adquirió gracias a la infracción tributaria.

No obstante, la legislación fiscal prevé la confiscación de los objetos que no han tributado y, si como en el supuesto enjuiciado, se ha dispuesto de ellos, una cantidad equivalente conforme al $\S 74$ c StGB. El Tribunal Supremo insiste en que esta medida tiene carácter de pena accesoria, por lo que, a diferencia del comiso, que no influye en la determinación de la pena, la confiscación sí puede suponer una reducción de la principal.

Por otra parte, el $\S 74$ a StGB permite confiscar objetos de un tercero cuando haya contribuido al menos por imprudencia a que se utilicen en la preparación o ejecución del delito. 
Pero el principio de proporcionalidad del $§ 74$ b StGB requiere que esa confiscación a personas distintas a los responsables penales esté suficientemente motivada.

En definitiva, el Tribunal Supremo delimita netamente el comiso y la confiscación como dos consecuencias separadas, considerando a la primera una medida patrimonial y la segunda una pena accesoria. Esto hace que en el comiso acepte una fundamentación escueta respecto a los indicios de la procedencia ilícita de los bienes, incluso en el ampliado, mientras en la confiscación precisa una motivación rigurosa que justifique su aplicación como pena añadida a la principal, que puede influir en esta condena.

\section{Conclusiones}

En el Derecho alemán la privación de las ganancias, efectos e instrumentos del delito se efectúa a través de dos instituciones distintas, el comiso regulado en los $\S \S 73$, a 73 e StGB, y la confiscación de los $\S \S 74$, a 74 d StGB. En nuestro ordenamiento el decomiso previsto en los artículos 127 a $128 \mathrm{CP}$ abarca la privación de todos esos bienes.

La primera figura, el comiso, comprende todas las ventajas patrimoniales obtenidas directamente del delito, ya sea una cantidad económica, un objeto, un derecho real, o incluso una facultad de uso. Además, puede extenderse a los bienes adquiridos con el precio de la venta del objeto delictivo, o en sustitución del mismo cuando es destruido o sufre daños. Se permite también acordarlo contra los terceros que lo obtuvieron conociendo su procedencia ilícita.

Cuando no es posible el comiso en esos casos, o el bien ha perdido valor, el tribunal debe imponer al autor o partícipe una cantidad equivalente.

No obstante, el principio de proporcionalidad se prevé en la ley con carácter imperativo, de forma que el comiso no debe decretarse cuando sea desproporcionado. Además, se puede 
prescindir de él si el afectado ya no posee el objeto ni su valor, o cuando sea de escasa entidad.

Por lo tanto, esta medida no comprende los productos del delito ni los instrumentos empleados en su preparación o ejecución, que se regulan en la confiscación.

Por otra parte, sólo se pueden decomisar bienes a terceros cuando los recibieron de mala fe, y la imposición de una cuantía sustitutiva se limita a los responsables penales, a diferencia del artículo 127 quáter $\mathrm{CP}$, que permite acordarlo frente a terceros cuando hubieran podido presumir el origen delictivo del objeto, e incluso exigirles una cuantía económica si ya no lo tienen en su poder. Por lo tanto, podría plantearse la hipótesis de que el tercero regale el bien sin saber que es ilegal y tenga que pagar su valor en dinero. La justificación del enriquecimiento ilícito que se aduce en el Derecho alemán aquí no es válida, sino que este pago parece revestir carácter de sanción, que se impone porque se presume que en realidad sí conocía esa procedencia ilícita. Por eso, entiendo que esta nueva regulación no resulta adecuada a los principios de proporcionalidad y culpabilidad.

En cuanto al contenido del comiso, el Tribunal Supremo mantiene que debe privarse del llamado "beneficio neto" obtenido por el delito, sin descontar los costes invertidos en su ejecución. Ahora bien, ha precisado que para calcular esa ventaja no se han de tener en cuenta los bienes que ya pertenecían al infractor cuando cometió el hecho, como sucede con los productos que se venden sin pagar los impuestos pertinentes o con el terreno no edificable que mediante soborno es calificado como urbanizable. Ni la mercancía ni el inmueble son beneficios del delito, sino tan solo la cuantía defraudada y el incremento del valor de la finca. Esta interpretación ha sido confirmada por el Tribunal Constitucional.

Respecto a su naturaleza, el Tribunal Supremo ha afirmado que el comiso no tiene finalidad penal, sino que persigue únicamente privar al responsable de la ventaja conseguida con el delito y con ello compensar la transferencia ilegal de riqueza. 
Por eso, la pena y el comiso son consecuencias diferentes sin interrelación entre sí, de modo que esta medida no da derecho a una reducción de la primera. Este carácter patrimonial ha sido avalado por el Tribunal Constitucional, concretamente al analizar la adecuación del comiso ampliado a la Ley Fundamental. Respecto a esta figura ha señalado que no tiene carácter de pena o sanción asimilada a ella. La desposesión no se dirige a captar la ventaja patrimonial obtenida delictivamente y a reprochar al afectado la realización de un hecho ilícito como origen de la misma, ni por tanto pretende causarle un mal retributivo. Más bien persigue unos fines de estabilización de la norma y de ordenación del patrimonio.

Sin embargo, junto al comiso se regula la confiscación, que busca privar de los efectos del delito y de los objetos utilizados en su preparación o ejecución, o destinados a este fin. Se trata de una institución completamente distinta a la anterior, a la que se atribuye naturaleza de pena accesoria, con las consecuencias que ello conlleva. El Tribunal Supremo ha declarado que debe tenerse en cuenta en la determinación de la pena, de modo que su imposición puede motivar una disminución de la pena principal, y que la motivación debe ser la exigida en este tipo de sanciones. Dado que en ocasiones se acuerda únicamente por razones de seguridad, el tribunal sentenciador ha de justificar si la impone por esta causa o con carácter retributivo. Por otra parte, debe renunciar a la confiscación siempre que resulte desproporcionada, o si la finalidad perseguida se puede lograr con medidas menos gravosas previstas en la ley.

Pues bien, el legislador español en la Exposición de Motivos de la LO 1/2015, de 30 de marzo, toma las declaraciones del Tribunal Constitucional alemán que se refieren exclusivamente al comiso, negando que se trate de una pena o sanción asimilada a ella. Pero como se ve, en Alemania esta medida comprende sólo las ventajas patrimoniales obtenidas por el delito. Junto a ella se regula la confiscación de los productos y de los instrumentos usados en la preparación y ejecución del hecho ilícito, y en este caso sí se considera que es una pena accesoria, 
plenamente sometida a los principios de estas sanciones. Desde esta perspectiva resultaría cuestionable el carácter civil y patrimonial de algunas formas de decomiso reguladas en nuestro Derecho, y en concreto la privación de los efectos e instrumentos a los responsables penales, cuando no se le quiten por razones de seguridad, como sucede con las armas o los útiles empleados para clonar tarjetas de crédito, etc., por ejemplo, la privación del vehículo con el que se transporta la droga. De atribuirse a estas consecuencias un carácter penal, como se hace en Alemania, algunas normas plantearían dudas incluso desde el punto de vista constitucional. Así sucede con el decomiso ampliado de los artículos 127 bis y quinquies-sexies $\mathrm{CP}$, que no sólo comprende las ganancias del delito, sino también los efectos e instrumentos. En este caso se permite practicarlo en virtud de una serie de presunciones respecto a la procedencia ilícita de los bienes. También el decomiso sin sentencia del artículo 127 ter CP, y el de los bienes transferidos a terceros, a los que según el artículo 127 quáter $\mathrm{CP}$, se les pueden requisar esos efectos e instrumentos, aunque no conocieran su procedencia ilegal, e imponer una cantidad equivalente si ya no los tenían en su poder. La adecuación de estas normas a los principios de culpabilidad y proporcionalidad que exige el Tribunal Supremo español es más que dudosa.

\section{Bibliografía}

ACQUAROLI, R.: "La fiscalidad de los sobornos", en ARROYO ZAPATERO, L./NIETO MARTÍN, A.: Fraude $y$ corrupción en el Derecho penal europeo, Eurodelitos de corrupción y fraude, Ediciones de la Universidad de Castilla-La Mancha, Cuenca, 2016.

AGUADO CORREA, T.: "La regulación del comiso en el Proyecto de modificación del Código penal", en Revista Electrónica de Ciencia Penal y Criminología, 05-04, 2003, (http://criminet.ugr.es/recpc).

AGUADO CORREA, T.: "Crónica de una reforma anunciada", en InDret, 1/2014, (www.indret.com). 
AGUADO CORREA, T.: "La Directiva 2014/42/UE sobre embargo y decomiso en la Unión Europea: una solución de compromiso a medio camino", en Revista General de Derecho Europeo, n 35, 2015, (www.iustel.com).

ALCÁZAR RAMOS, M.: "Corrupción política, Derechos fundamentales y opinión pública", en JAREÑO LEAL, Á./ DOVAL PAIS, A.: Corrupción pública, prueba y delito: cuestiones de libertad e intimidad, Aranzadi, Pamplona, 2015.

BACIGALUPO, S./LIZCANO, J.: Responsabilidad penal y administrativa de las personas jurídicas en delitos relacionados con la corrupción, Colección Estudios, $\mathrm{n}^{\mathrm{0}}$ 1, Eurosocial, Madrid, 2013, (http://sia.eurosocial-ii.eu/files/ docs/1400660079-E1.pdf).

BLANCO CORDERO, I.: "Recuperación de activos de la corrupción mediante el decomiso sin condena (comiso civil o extinción de dominio)", en FABIÁN CAPARRÓS, E.A./ONTIVEROS ALONSO, M./RODRÍGUEZ GARCÍA, N. (Ed.): El Derecho penal y la política criminal frente a la corrupción, Ibijus, México, 2012.

BLANCO CORDERO, I.: "La aplicación del comiso en caso de adjudicación de contratos públicos obtenida mediante soborno de funcionarios públicos", en Estudios Penales y Criminológicos, $\mathrm{n}^{\mathrm{0}}$ 27, 2007.

BLANCO CORDERO, I.: "El decomiso de las ganancias de la corrupción”, en Revista Eletrônica de Direito Penal, vol. $1, \mathrm{n}^{\mathrm{o}} 1,2013$.

CAMPOS NAVAS, D.: "Comiso y medidas cautelares. Regulación vigente y reformas en tramitación”, en Cuadernos Digitales de Formación, Consejo General del Poder Judicial, $n^{\circ} 29,2013$.

DE LA CUESTA ARZAMENDI, J.L.: "Iniciativas internacionales contra la corrupción", en Eguzkilore, n 17, 2003.

DE LA CUESTA ARZAMENDI, J.L.: "La corrupción ante el Derecho y la justicia", en Diritto Penale Contemporaneo, 2014, (http://www.penalecontemporaneo.it/upload/ 1388929330DELACUESTA_2014a.pdf).

hitp://dx.doi.org/10.15304/epc.38.4473 -601- vol. XXXVIII (ext.) (2018). ISSN $1137.7550: 547-604$ 
DE LA MATA BARRANCO, N.J.: “¿Qué interés lesionan las conductas de corrupción?", en Eguzkilore, no 23, 2009, (http://www.ehu.eus/documents/1736829/2176697/19De+la+Mata.indd.pdf).

ENGERER, U.: Folgen und Bekämpfung von Korruption: liefern ökonomische Ansätze bestechende Argumente?, en Diskussionspapiere, Deutsches Institut für Wirtschaftsforschung, $\mathrm{n}^{\mathrm{o}}$ 161, 1998, (https://www.diw.de/documents/publikationen/73/diw_01.c.38637.de/dp161.pdf).

ESER, A.: "Neue Wege der Gewinnabschópfung im Kampf gegen die organisierte Kriminalitat?", en DENCKER, F. (Coord.): Beiträge zur Rechtswissenschaft. Festschrift Walter Stree und Johannes Wessels zum 70. Geburtstag, C.F. Müller Juristischer Verlag, Heidelberg, 1993.

FARALDO CABANA, P.: "La regulación del comiso en España. Especial referencia a los comisos específicos en los delitos de tráfico de drogas, blanqueo de bienes y contrabando", en Revista Peruana de Ciencias Penales, $\mathrm{n}^{\mathrm{o}} 20$, 2008, (http://www.ecrim.es).

FISCHER, T.: Strafgesetzbuch und Nebengesetze, 59 Auflage, Verlag. C.H.Beck, München, 2012.

JESCHECK, H.H.: Tratado de Derecho penal. Parte general, Comares, Granada, 2002.

KINDHÄUSER, U.: "Presupuestos de la corrupción punible en el estado, la economía y la sociedad. Los delitos de corrupción en el Código penal alemán", en Política Criminal, vol. 2, no 3, 2007, (http://www.politicacriminal. $\mathrm{cl} / \mathrm{n}$ _03/a_1_3.pdf).

KINDHÄUSER, U.: Strafgesetzbuch. Lehr- und Praxiskommentar, 5 Auflage, Nomos, Baden-Baden, 2013.

KÜHL, K.: Strafgesetzbuch Kommentar, 27 Auflage, Verlag. C.H.Beck, München, 2011.

MANZANARES SAMANIEGO, J.L.: "Aproximación al comiso del nuevo artículo 344 bis e) del Código penal (Ley Orgánica 1/1988, de 24 de marzo, de reforma del Código penal en materia de tráfico ilegal de drogas. «B.O.E.» de 
26 del mismo mes)", en Boletín de Información. Ministerio de Justicia e Interior, $\mathrm{n}^{\circ} 1500$ a 1502, 1988, (http:// www.mjusticia.gob.es).

MANZANARES SAMANIEGO, J.L.: "El Comiso y la Caución en la propuesta de nuevo Anteproyecto de Código penal", en Boletín de Información. Ministerio de Justicia e Interior, $\mathrm{n}^{\circ} 38$ (1342), 1984, (http://www.mjusticia.gob.es).

PUENTE ABA, L.M.: "La regulación del comiso en el Código penal español", Centro de Investigación Interdisciplinaria en Derecho Penal Económico, Córdoba, Argentina, 2009, (www.ciidpe.com.ar).

RHODE, M.: "El comiso según el art. 73.3 StGB", en WISTRA, $\mathrm{n}^{\mathrm{o}}$ 3, 2012, (https://beck-online.beck.de/?vpath=bibdata $\% 2$ Fzeits $\% 2$ FWISTRA $\% 2 F 2012 \% 2$ Fcont $\% 2$ FWISTRA $\% 2 \mathrm{E} 2012 \% 2 \mathrm{Ehtm})$.

SÁNCHEZ GARCÍA DE PAZ, I.: La criminalidad organizada. Aspectos penales, procesales, administrativos y policiales, Ministerio del Interior, Dykinson, Madrid, 2005.

SATGER, H./SCHMITT, B./WIDMAIER, W.: Strafgesetzbuch Kommentar, Carl Heymann Verlag, München, 2009.

SCHÖNKE, A./SCHRÖDER, H.: Strafgesetzbuch Kommentar, 28 Auflage, Verlag. C.H.Beck München, 2014.

SILVA CASTAÑO, M.L.: "La nueva Directiva sobre el comiso", en Aranzadi Doctrinal, no 3, 2015, (https://insignis. aranzadidigital.es).

SUCHY, O.: Der Verfall im Ordnungswidrigkeitenrecht. Eine Untersuchung ausgewählter Gesichtspunkte im wirtschaftsstrafrechtlichen Kontext, Herbert Utz, München, 2014.

TRÖNDLE. H./FISCHER, T.: Strafgesetzbuch und Nebengesetze, C.H.Beck'sche Verlagsbuchhandlung, München, 2006.

VÁZQUEZ-PORTOMEÑE SEIJAS, F.: “Admisión de regalos y corrupción pública. Consideraciones político criminales sobre el llamado «cohecho de facilitación» (art. 422 $\mathrm{CP})$ ", en Revista de Derecho Penal y Criminología, $\mathrm{n}^{\mathrm{o}}$ 6, 2011.

hitp://dx.doi.org/10.15304/epc.38.4473 -603- vol. XXXVIII (ext.) (2018). ISSN $1137.7550: 547-604$ 
VIZUETA FERNÁNDEZ, J.: "El comiso de las ganancias provenientes del delito y el de otros bienes equivalentes a éstas", en Revista Penal, n 19, 2007.

WOLF, S.: "Die Modernisierung des deutschen Antikorruptionsstrafrechts durch internationale Vorgaben. Momentaufnahme und Ausblick", Neue Juristische Wochenschrift, vol. 59, n 38, 2006 